\title{
Wealth Dynamics in a Bond Economy with Heterogeneous Beliefs
}

\author{
Timothy Cogley* \\ Thomas J. Sargent** \\ Viktor Tsyrennikov***
}

The views expressed herein are those of the author and do not necessarily reflect the official views of The Bank of Korea. When reporting or citing it, the author's name should always be stated explicitly.

\footnotetext{
* New York University. Email: tim.cogley@nyu.edu.

** New York University and Hoover Institution. Email: thomas.sargent@nyu.edu. *** Cornell University. Email: vt68@cornell.edu.
}

For comments, criticisms, and suggestions, we thank the referee, editor, and Aslak Bakke Kvinlog as well as seminar participants at Georgetown, Northwestern, NYU, and the September 2011 Cornell/ Penn State Macroeconomics Conference. 


\section{Contents}

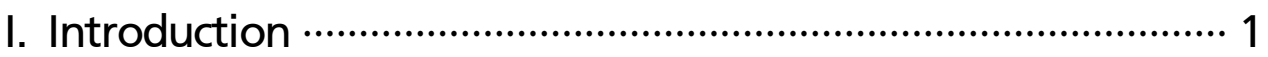

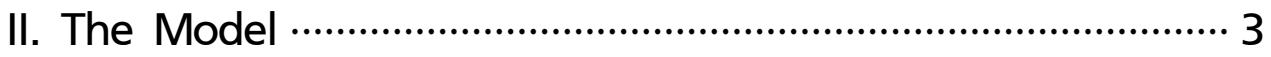

1. Preferences

2. The aggregate endowment and its distribution ….................... 4

3. Information and beliefs ….................................................... 5

III. A Complete-Markets Benchmark ……............................... 7

1. Asset markets, budget constraints, and debt limits ……………….... 7

2. Complete-markets equilibrium ………………............................... 8

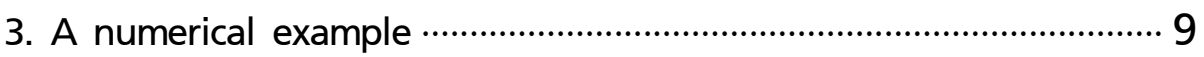

IV. A Bond Economy …............................................................ 16

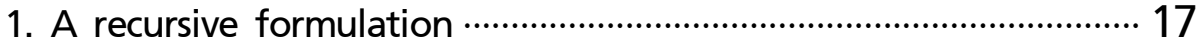

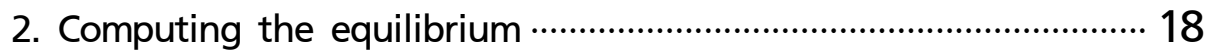

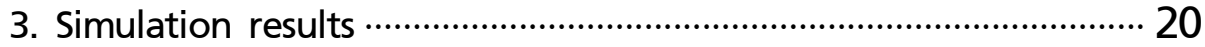

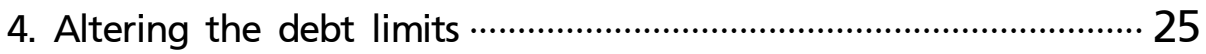

5. A dogmatic-beliefs economy …………………………………… 26

V. Intermediate economies …............................................... 27

VI. Related literature …......................................................... 30

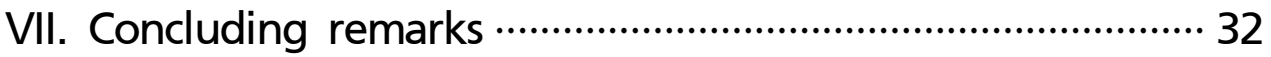

Appendices …....................................................................... 33

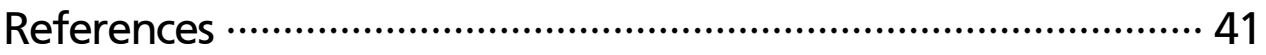




\section{Wealth Dynamics in a Bond Economy with Heterogeneous Beliefs}

Two types of agents have diverse beliefs about the law of motion for an exogenous endowment. One type knows the true law of motion and the other learns about it via Bayes' theorem. Financial market structure affects the dynamics of the distribution of financial wealth. When markets are complete, the learning agent loses wealth, as in Blume and Easley (2006). The absence of markets for some Arrow securities alters the direction in which wealth is transferred relative to a complete markets economy. In an economy in which only a risk-free bond is traded, the learning agent accumulates wealth, both agents survive asymptotically, and the more knowledgeable agent is driven to his debt limit.

Keywords: Wealth dynamics, survival, incomplete markets, diverse beliefs, learning

JEL Classification: D52, D53, D83, D84 


\section{Introduction}

We study how market incompleteness affects the distribution of wealth when beliefs are heterogeneous. Blume and Easley (2006) describe conditions that verify Friedman's (1953, p. 22) assertion that competition will produce outcomes in which agents with more accurate probability assessments accumulate wealth at the expense of agents with less accurate ones. Those wealth dynamics imply that asset prices eventually reflect only better informed agents' beliefs. Blume and Easley show that when markets are complete and allocations are Pareto optimal, agents who know less or estimate more parameters lose wealth while they learn. However, Blume and Easley also provide examples showing that agents' incorrect beliefs need not make them lose wealth when markets are incomplete. ${ }^{1)}$

Similarly, Cogley and Sargent (2009) study aspects of the transition in a competitive complete-markets economy, including the rate at which less well informed consumers lose wealth, how wealth is transferred between more and less well informed consumers, and how their financial positions affect subjective prices of risk. Cogley and Sargent's model is populated by two types of consumers, one that knows the true transition probabilities for an exogenous Markov endowment and another that learns about them. The less well informed consumers are pessimistic, initially overestimating the probability of a contraction state. Because of their pessimism, there is a sense in which Arrow securities paying off in the contraction state are overpriced relative to the probabilities held by the better informed agents, while those paying off in an expansion state are underpriced. Those price gaps open attractive trading opportunities. Better informed consumers buy what they regard as low-priced expansion-state securities and sell high-priced contraction-state securities. They grow rich on average because the expansion state occurs more often and the contraction state less often than less well informed agents expect. But when a contraction occurs, not only do better informed consumers suffer a decline in their endowments, but they are also obliged to pay off on their contraction-state liabilities. Because their financial positions increase their exposures to catastrophic risk, their subjective

1) See also Sandroni (2005), Coury and Sciubba (2010), Beker and Chattopadhyay (2010), Cao (2011), and Tsyrennikov (2011). We discuss this work in section VI. 
prices of risk are high during the learning transition. And since less well informed consumers buy 'contraction insurance,' their subjective prices of risk are low.

In the Cogley-Sargent model, the ability to trade a complete set of Arrow securities is central to the mechanism by which better informed consumers grow rich at the expense of less well informed consumers. Complete markets give agents many opportunities to make trades motivated solely by the different subjective probabilities they may put on future outcomes. In this paper, we study what happens when some Arrow-security markets are closed. For a model very much like that of Cogley and Sargent, we find that the direction in which wealth is transferred is reversed when agents can trade only a risk-free bond. Less well informed consumers accumulate financial assets, and better informed consumers are driven to debt limits. Both agents survive asymptotically, with better informed agents rolling over their debt forever.

Precautionary motives play a central role. Because less well informed consumers are pessimistic, their precautionary motives are stronger than they would be in a rational expectations version of the model. When markets are complete, more cautious agents can guard against deep contractions by purchasing an Arrow security that pays off in that state. They lose wealth on average because those states occur less often than they expect. In a risk-free bond only economy, more cautious agents guard against deep contractions by accumulating risk-free bonds. The real interest rate adjusts to make better informed agents content to sell risk-free bonds. This reverses the direction in which wealth is transferred along the transition during which the less informed agent is still learning.

Cogley et al. (2012) extend the analysis undertaken in this paper to study the impact of diverse beliefs on market prices of risk. There we demonstrate that what we can call rational-expectations prices of risk are higher in the bond economy than under complete markets and that they exceed Hansen and Jagannathan's (1991) lower bound. Much of the volatility in the rational-expectations pricing kernel arises from a multiplicative wedge that measures belief differentials. The wedge is positively correlated with the IMRS in the bond economy but negatively correlated under complete markets. Variation in the rational-expectations pricing kernel is therefore greater in the bond economy. 


\section{The Model}

Time is discrete and is indexed by $t \in\{0,1,2, \cdots\}$. The set of possible states is the finite set $G$ of all possible realizations of the aggregate income growth rate. The set of all histories of the state is denoted by $\sum$. The partial history of the state through date $t$ is denoted by $g^{t}$. The set of all partial histories of length $t$ is $\Sigma^{t}$. We will also make use of a "true" probability measure on $\sum$ denoted by $\pi^{0}$.

\section{Preferences}

There are two types of consumers, indexed by $i=1,2$. Agent $i$ ranks consumption plans $c=\left\{c\left(g^{t}\right): \forall t, \forall g^{t} \in \Sigma^{t}\right\}_{t=0}^{\infty}$ using a time-separable, isoelastic welfare function:

$$
U^{i}(c)=E^{i} \sum_{t=0}^{\infty} \beta^{t} u\left(c\left(g^{t}\right)\right), \quad \beta \in(0,1)
$$

where

$$
u(c)=\frac{c^{1-\gamma}}{1-\gamma}
$$

We assume that the preference parameters $\beta$ and $\gamma$ are the same across types but that the consumers differ in how they form expectations. The expectation operator $E^{i}$ signifies that each type forms predictions by averaging with respect to its own subjective probability distribution over future outcomes. Consumers choose consumption and savings plans to maximize expected utility subject to flow budget constraints and debt limits to be specified below. 


\section{The aggregate endowment and its distribution}

The two types receive constant shares $\left(\phi^{1}, \phi^{2}\right)$ of a non-storable aggregate endowment $y\left(g^{t}\right)$,

$$
y^{i}\left(g^{t}\right)=\phi^{i} y\left(g^{t}\right), \quad i=1,2
$$

where $\phi^{1}+\phi^{2}=1$. Growth in the aggregate endowment can take one of three values $G \equiv\left\{g_{h}, g_{m}, g_{d}\right\}$. The high-growth state represents an expansion, the medium-growth state is a mild recession, and the low-growth state is a deep contraction or disaster. We refer to the respective states as expansions, recessions, and contractions. These outcomes depend on the realization of two independent random variables, $s$ and $d$. The random variable $s$ is a Markov-switching process with transition matrix,

$$
\Pi_{s}=\left[\begin{array}{cc}
p_{11} & 1-p_{11} \\
1-p_{22} & p_{22}
\end{array}\right]
$$

The random variable $d$ is an i.i.d. Bernoulli variate with success probability $p_{d}$. The mapping from $(s, d)$ realizations to growth outcomes is as follows:

$$
g=\left\{\begin{array}{l}
g_{h} \text { when } s=1 \text { and } d=1 \text { or } d=2 \\
g_{m} \text { when } s=2 \text { and } d=1 \\
g_{d} \text { when } s=2 \text { and } d=2
\end{array}\right.
$$

The expansion state occurs when $s=1$ independently of the outcome for $d$, a recession occurs when $s=2$ and $d=1$, and a contraction occurs when $s=d=2$. The resulting transition matrix for growth states is:

$$
\Pi_{g}=\left[\begin{array}{ccc}
p_{11} & \left(1-p_{11}\right)\left(1-p_{d}\right) & \left(1-p_{11}\right) p_{d} \\
1-p_{22} & p_{22}\left(1-p_{d}\right) & p_{22} p_{d} \\
1-p_{22} & p_{22}\left(1-p_{d}\right) & p_{22} p_{d}
\end{array}\right]
$$




\section{Information and beliefs}

Because learning statistics become part of the state vector, we want to reduce the learning problem to a single unknown parameter. Toward that end, we assume that $\Pi_{s}$ is known to both agents and that $p_{d}$ is known only to agent 2 . It follows from (6) that agent 2 knows the true transition matrix $\Pi_{g}$, while agent 1 does not. Agent 1 learns about $p_{d}$ by applying Bayes' theorem.

Both agents observe realizations of $g_{t}$ but not realizations of the underlying random variables $\left(s_{t}, d_{t}\right)$. Because $s$ and $d$ are independent and $g_{h}$ can occur when $d$ equals 1 or 2 , entry into the expansion state conveys no information about $p_{d}$. Information about $d$ is revealed only when the economy moves into a recession or contraction.2)

We assume that less well informed, type-1 consumers have identical beta priors on $p_{d}$,

$$
f\left(p_{d}\right)=B\left(n_{0}, m_{0}\right)
$$

where $n_{0}-1$ is the prior number of disasters $(d=2)$ and $m_{0}-1$ is the prior number of non-disasters $(d=1)$. It follows that the prior mean for $p_{d}$ is $\hat{p}_{d}=n_{0} /\left(n_{0}+m_{0}\right)$.

Because $d$ is an i.i.d. Bernoulli random variable, the likelihood function is proportional to

$$
f\left(g^{t} \mid p_{d}\right) \propto p_{d}^{n_{t}} \cdot\left(1-p_{d}\right)^{m_{t}}
$$

where $g^{t}$ represents the observed history of $g_{t}$, and $m_{t}$ and $n_{t}$ are the number of recessions and contractions, respectively, counted through date $t$. These counters evolve according to

2) The second and third columns of $\Pi_{g}$ depend on $p_{d}$, but the first column does not. 


$$
\left(n_{t+1}, m_{t+1}\right)=\left\{\begin{array}{cl}
\left(n_{t}, m_{t}\right) & \text { when } g_{t+1}=g_{h} \\
\left(n_{t}, m_{t}+1\right) & \text { when } g_{t+1}=g_{m} \\
\left(n_{t}+1, m_{t}\right) & \text { when } g_{t+1}=g_{d}
\end{array}\right.
$$

Since the prior is beta and the likelihood function is binomial, the posterior is also a beta density,

$$
f\left(p_{d} \mid g^{t}\right)=B\left(n_{0}+n_{t}, m_{0}+m_{t}\right)
$$

The posterior predictive density over a potential future trajectory $g_{t}^{f}$ emanating from $g^{t}$ is

$$
f\left(g_{t}^{f} \mid g^{t}\right)=\int f\left(g_{t}^{f} \mid p_{d}, g^{t}\right) f\left(p_{d} \mid g^{t}\right) d p_{d}
$$

Type-1 consumers form expectations by averaging potential future sequences with weights assigned by $f\left(g_{t}^{f} \mid g^{t}\right)$. Their one-step ahead transition matrix is

$$
\Pi_{g t}^{1}=\left[\begin{array}{ccc}
p_{11} & \left(1-p_{11}\right)\left(1-\hat{p}_{d t}\right) & \left(1-p_{11}\right) \hat{p}_{d t} \\
1-p_{22} & p_{22}\left(1-\hat{p}_{d t}\right) & p_{22} \hat{p}_{d t} \\
1-p_{22} & p_{22}\left(1-\hat{p}_{d t}\right) & p_{22} \hat{p}_{d t}
\end{array}\right]
$$

where $\hat{p}_{d t}=\left(n_{0}+n_{t}\right) /\left(n_{0}+n_{t}+m_{0}+m_{t}\right)$ is the posterior mean.3) The better informed type- 2 consumers form expectations using the true transition probabilities $f\left(g_{t}^{f} \mid p_{d}, g^{t}\right)$. Because our model satisfies the conditions of a Bayesian consistency theorem, differences in beliefs vanish eventually. However, learning will be slow because opportunities to learn arise only in recessionsorcontractions, which occur in 1 year out of 7 for our calibration. Hence differences in beliefs remain active for quite some time.

Following Cogley and Sargent (2009), we study Walrasian equilibria in which

3) For recursive versions of the model, the one-step transition matrix is all we need. 
traders take prices as given and do not infer information from prices. We put individuals in a setting in which the only information revealed by prices is subjective probabilities over future endowment paths. We short-circuit the problem of learning from prices by endowing agents with common information sets along with knowledge of each other's prior. With this simplification, agents learn nothing from prices because there is nothing to learn.4)

\section{A Complete-Markets Benchmark}

As a point of departure, we study how the model behaves when markets are complete. We therefore temporarily assume that a full set of Arrow securities is traded, one for each of the aggregate growth states. ${ }^{5}$ ) Our preliminary objective is to establish a link with previous literature. We first establish that our model with complete markets behaves in much the same way as those of Blume and Easley (2006) and Cogley and Sargent (2009). In sections IV and V, we address how outcomes change when markets are incomplete.

\section{Asset markets, budget constraints, and debt limits}

An Arrow security $j$ bought in period $t$ pays one unit of consumption in period $t+1$ if the growth state $g_{t+1}=j$ is realized and zero units otherwise. The security that pays in state $g_{t+1}=j$ trades at price $Q\left(g_{t+1}=j \mid g^{t}\right)$.

After history $g^{t}$, the flow budget constraint for agent $i$ is

$$
y^{i}\left(g^{t}\right)+a^{i}\left(g_{t}=k \mid g^{t-1}\right) \geq c^{i}\left(g^{t}\right)+\sum_{j \in G} Q\left(g_{t+1}=j \mid g^{t}\right) a^{i}\left(g_{t+1}=j \mid g^{t}\right)
$$

4) Grossman(1981) distinguishes between rational expectations models in which some agents extract information from prices and Walrasian models in which agents learn nothing from prices.

5) Payoffs cannot be contingent on the realization of the disaster-state random variable $d$ because it is unobserved. 
The variable $y^{i}\left(g^{t}\right)$ is nonfinancial income, $a^{i}\left(g_{t+1}=j \mid g^{t}\right)$ denotes purchases at history $g^{t}$ of the Arrow security paying off when $g_{t+1}=j$, and $c^{i}\left(g^{t}\right)$ is consumption. When there is no risk of confusion, we will denote Arrow securities prices and quantities as $Q_{j}\left(g^{t}\right)$ and $a_{j}\left(g^{t}\right)$, respectively.

Individuals can borrow by taking negative positions in Arrow securities subject to a debt limit. For the complete-markets version of our model, we adopt the natural borrowing limit, which constrains total borrowing to be no greater than the maximum that can be repaid with certainty,

$$
\widetilde{B^{i}}\left(g^{t}\right)=\sum_{\tau=t}^{\infty} \sum_{g^{\tau} \in \Sigma^{\tau}} Q\left(g^{\tau} \mid g^{t}\right) y^{i}\left(g^{\tau}\right)
$$

where $Q\left(g^{\tau} \mid g^{t}\right) \equiv Q\left(g^{\tau} \mid g^{\tau-1}\right) \cdots Q\left(g^{t+1} \mid g^{t}\right)$. This borrowing limit equals the history- $g^{t}$ value of the continuation of agent $i$ 's endowment stream. This represents the amount of debt service consumer $i$ could sustain if all future income were devoted to that purpose. Notice that the natural borrowing limit is in general historyand individual-dependent.

\section{Complete-markets equilibrium}

Because the endowment is perishable, the aggregate resource constraint is

$$
y\left(g^{t}\right) \equiv y^{1}\left(g^{t}\right)+y^{2}\left(g^{t}\right)=c^{1}\left(g^{t}\right)+c^{2}\left(g^{t}\right), \quad \forall t, g^{t} \in \Sigma^{t}
$$

Since Arrow securities are in zero net supply, financial markets clear when

$$
a_{j}^{1}\left(g^{t}\right)+a_{j}^{2}\left(g^{t}\right)=0, \quad \forall t, g^{t} \in \Sigma^{t}, \quad j \in G
$$

Initial endowments of Arrow securities are given and satisfy this market-clearing condition.

We seek a recursive competitive equilibrium in which: (i) individuals formulate 
consumption, savings, and portfolio plans by maximizing subjective expected utility; (ii) beliefs are updated via Bayes theorem; (iii) flow budget constraints and borrowing limits are satisfied; (iv) consumption plans respect the aggregate-resource constraint; and (v) security prices adjust so that financial markets clear.

Appendix A describes a recursive formulation for the model and outlines an algorithm for computing its equilibrium. The algorithm exploits the fact that a competitive equilibrium solves a Pareto problem. We use a modified Negishi algorithm that replaces Pareto weights with an initial distribution of consumption. The solution to the Negishi problem tells us how to compute consumption plans for each agent recursively. Asset prices are calculated from subjective Euler equations. Then the consumption plans and price system are used to back out asset-trading plans. The last step delivers an initial wealth distribution that supports the computed prices and allocations as a competitive equilibrium. This relation can be inverted to compute a competitive equilibrium for any initial wealth distribution.

\section{A numerical example}

Our model is a special case of one of Blume and Easley's complete-markets frameworks. Because the beliefs of type- 2 consumers are correct and more parsimonious than those of type-1 individuals, Blume and Easley's results imply that

$$
\lim \sup _{t \rightarrow \infty} \hat{c}^{1}\left(g^{t}\right)=0
$$

where $\hat{c}^{1}\left(g^{t}\right)$ represents the consumption share of type-1 consumers. Type-1 consumers eventually come arbitrarily close to exhausting their borrowing capacity, after which time their consumption is arbitrarily close to zero.6) In that sense, type-2 agents are the only ones who survive in a competitive equilibrium.

Cogley and Sargent (2009) study a transition while some agents are learning. To make contact with their model, we turn to a simulation. The time period is one

6) Since the one-period utility function satisfies the Inada conditions, the natural borrowing limit never actually binds in equilibrium. 
year, the discount factor $\beta=1.04^{-1}$, and the coefficient of relative risk aversion is $\gamma=2$. The endowment process is calibrated so that the high-growth state $g_{h}$ represents an expansion, the medium-growth state $g_{m}$ a mild recession, and the lowgrowth state $g_{d}$ a deep contraction,

$$
g_{h}=1.03, \quad g_{m}=0.99, \quad g_{d}=0.90
$$

The true transition probabilities $\Pi_{g}$ are calibrated so that the economy spends most of its time in the expansion state and visits the contraction state rarely,

$$
p_{11}=0.917, \quad p_{22}=0.50, \quad p_{d}=0.10
$$

These numbers imply that an expansion has a median duration of 8 years, that a recession has a median duration of 1 year, and that 1 in 10 downturns are deep. The implied one-step transition matrix is

$$
\Pi_{g}=\left[\begin{array}{lll}
0.917 & 0.0747 & 0.0083 \\
0.50 & 0.45 & 0.05 \\
0.50 & 0.45 & 0.05
\end{array}\right]
$$

and the ergodic probabilities are

$$
\operatorname{pr}\left(g_{h}\right)=0.8576, \quad \operatorname{pr}\left(g_{m}\right)=0.1281, \quad \operatorname{pr}\left(g_{d}\right)=0.0142
$$

The unconditional probability of a contraction is therefore in the same ball-park as estimates of Barro and co-authors.7) Finally, we assume that each agent receives 50 percent of the aggregate endowment in each period: $\phi^{i}=0.5, i=1,2 .{ }^{8}$ )

Following Cogley and Sargent (2009), we assume that less well informed type-1 consumers are initially pessimistic, over-estimating the probability of a contraction. In particular, we assume their prior is

7) E.g., see Barro (2006), Barro and Ursua (2008), and Barro, Nakamura, Steinsson, and Ursua (2011).

8) How $\phi^{i}$ is calibrated matters quantitatively but not qualitatively. Our main insights remain valid for economies with $\phi^{1}=0.2$ and 0.8 . 


$$
p_{d} \sim B(5,5)
$$

implying a prior mean $\hat{p}_{d 0}=0.50$. The implied prior transition and long-run probabilities are

$$
\Pi_{g 0}^{1}=\left[\begin{array}{lll}
0.917 & 0.0415 & 0.0415 \\
0.50 & 0.25 & 0.25 \\
0.50 & 0.25 & 0.25
\end{array}\right]
$$

and

$$
p r^{1}\left(g_{h}\right)=0.8576, p r^{1}\left(g_{m}\right)=0.0712, p r^{1}\left(g_{d}\right)=0.0712
$$

respectively. Type-1 consumers therefore initially overestimate the likelihood of contractions and underestimate that of recessions. Appendix B demonstrates that type-1 consumers are only moderately pessimistic, however, in the sense that their priors would be statistically difficult to distinguish from those of type-2 consumers in samples 50 years long. Their pessimism dissipates as events unfold, but this happens slowly because opportunities to learn about $p_{d}$ arise only in recessions or contractions.

We simulate 10,000 sample paths for $g_{t}$, each of length 200 years. Along each path, we compute consumption and financial wealth for each agent as well as equilibrium prices of Arrow securities. Figures 1-3 summarize the results.

We begin by examining prices for Arrow securities and comparing them with outcomes in the homogeneous-beliefs rational-expectations version of the model. Because natural borrowing limits never bind in equilibrium, Arrow-security prices can be expressed as

$$
Q\left(g_{t+1} \mid g_{t}\right)=Q^{H B}\left(g_{t+1} \mid g_{t}\right)\left[\hat{c}^{1}\left(g_{t}\right)\left(\frac{\pi^{1}\left(g_{t+1} \mid g_{t}\right)}{\pi^{2}\left(g_{t+1} \mid g_{t}\right)}\right)^{1 / \gamma}+\left(1-\hat{c}^{1}\left(g_{t}\right)\right)\right]^{\gamma}
$$

where 


$$
Q^{H B}\left(g_{t+1} \mid g_{t}\right)=\beta g_{t+1}^{-\gamma} \pi^{2}\left(g_{t+1} \mid g_{t}\right)
$$

represents security prices in the homogeneous-beliefs economy with only type- 2 consumer.

Figure 1 plots the ratio of ensemble averages of Arrow security prices in the diverse-beliefs and homogeneous-beliefs economies, respectively. Since these prices coincide when consumers agree about transition probabilities, the ratios converge to one in the long run. Furthermore, because all consumers agree about transition probabilities into the expansion state, the two sets of prices always coincide for the security paying off in that state (see column 1). Disagreements emerge about transition probabilities for entering recessions and contractions. Conditional on the consumption share, $Q\left(g_{t+1} \mid g_{t}\right)$ is increasing in the probability ratio $\pi^{1}(\cdot) / \pi^{2}(\cdot)$, implying that Arrow securities are overpriced relative to homogeneous-beliefs valuations when $\pi^{1}(\cdot)>\pi^{2}(\cdot)$ and underpriced when $\pi^{1}(\cdot)<\pi^{2}(\cdot)$. Since type-1 consumers overestimate the probability of contractions and underestimate that of recessions, the recession-state security is underpriced relative to its homogeneous-beliefs valuation (column 2) while the contraction-state security is overpriced (column 3).

Figure 1: Average prices of Arrow securities
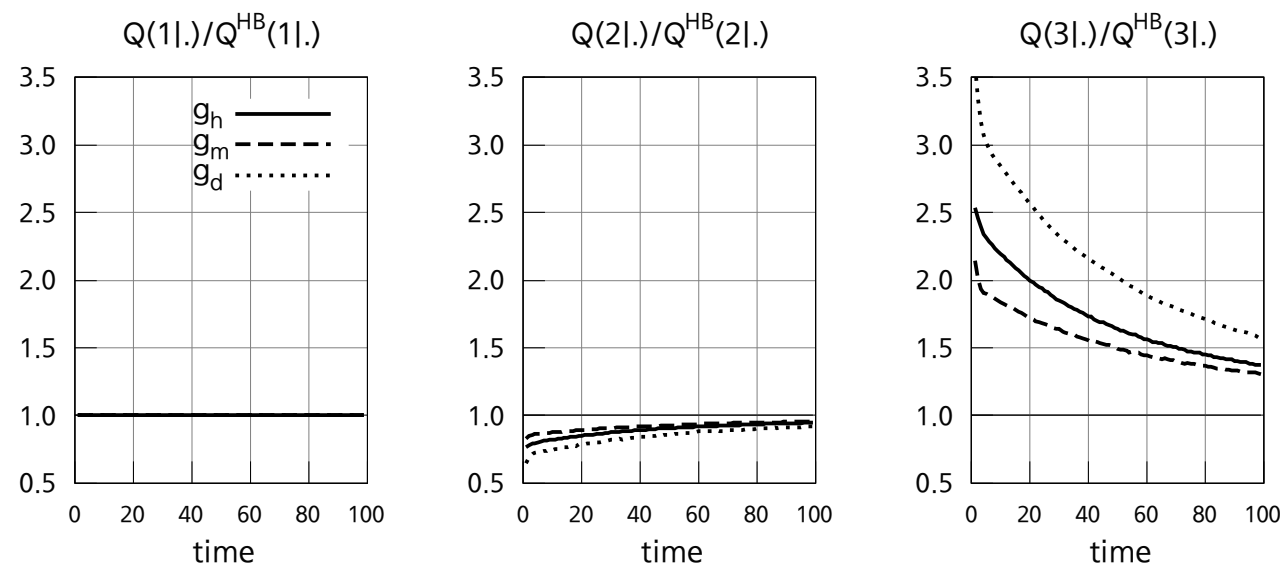
Prices eventually converge to homogeneous-beliefs rational-expectations values, but convergence is slow, with substantial gaps remaining after 100 years. Type-1 consumers learn slowly because they update their posteriors for $p_{d}$ only in recessions or contractions, which occur roughly 14 percent of the time. Many years must pass before a large sample of recessions/contractions is available.

Well informed Type-2 consumers regard these price gaps as providing attractive trading opportunities. They believe the contraction-state security will pay off less often and that the recession-state security will pay off more often than Type-1 consumers. They sell 'overpriced' contraction securities and buy 'underpriced' recession securities, while Type-1 consumers take opposite positions. Type-1 consumers therefore pay out on their financial liabilities when a recession occurs, while Type-2 consumers pay out in the event of a contraction.

Type-2 consumers profit on average from these trades because recession-state securities do in fact pay off more often and contraction-state securities less often than Type-1 consumers expect. The consequences for consumption and wealth are shown in figure 2. The left column portrays cross-sample-path averages of consumption and financial wealth for the two agents, both normalized as a proportion of aggregate income.9) Consistent with the results of Blume and Easley (2006), the less well informed agent 1 loses wealth quickly. His average debt is roughly 3 times aggregate income after 20 years and 4 times income after 50 years. As his liabilities accumulate, more and more of his income is devoted to debt service, and his consumption declines. Eventually he is driven to the vicinity of his borrowing limit and effectively exits the economy, although this rarely occurs within the first 100 years.

More formally, because the natural borrowing limit is slack in equilibrium, an analytical expression can be found for growth in the consumption share. After dividing agent 1's Euler equation by that of agent 2 and re-arranging terms, we find

$$
\frac{\hat{c}^{1}\left(g_{t+1}\right)}{\hat{c}^{1}\left(g_{t}\right)}=\left[\hat{c}^{1}\left(g_{t}\right)+\left(1-\hat{c}^{1}\left(g_{t}\right)\right)\left(\frac{\pi^{2}\left(g_{t+1} \mid g_{t}\right)}{\pi^{1}\left(g_{t+1} \mid g_{t}\right)}\right)^{1 / \gamma}\right]^{-1}
$$

When consumers agree on transition probabilities, $\pi^{1}(\cdot)=\pi^{2}(\cdot) P$, their con-

9) Multiply by 2 to measure them as proportions of individual income. 
sumption shares remain unchanged. Consumption shares therefore remain constant when the economy transitions into an expansion. Because agent 1 is usually pessimistic about contractions, his consumption share declines when the economy transitions into a recession, $\pi^{1}\left(g_{m} \mid g_{t}\right)<\pi^{2}\left(g_{m} \mid g_{t}\right)$, and it increases when the economy transitions into a contraction, $\pi^{1}\left(g_{d} \mid g_{t}\right)>\pi^{2}\left(g_{d} \mid g_{t}\right)$. Because disasters are infrequent, agent 1's consumption share trends down on average.

The right panel of figure 2 portrays quantiles of the consumption and wealth distributions for agent 2. Percentiles are computed date-by-date from the respective cross-sample-path distributions. Consistent with the previous results, agent 2's median wealth drifts upward over time, as does his median share of consumption. Notice, however, that the marginal distributions are skewed to the left, and there is a small probability that agent 2's wealth and consumption shares decline over time. Agent 2 bets aggressively against deep contractions. With small probability, some sample paths emerge with many deep contractions, and agent 2's bets turn out badly. Those paths account for the lower tails shown in the figure.

Figure 2: Wealth and consumption dynamics under complete markets. Financial wealth is measured in multiples of the aggregate endowment.

a) Average consumption share

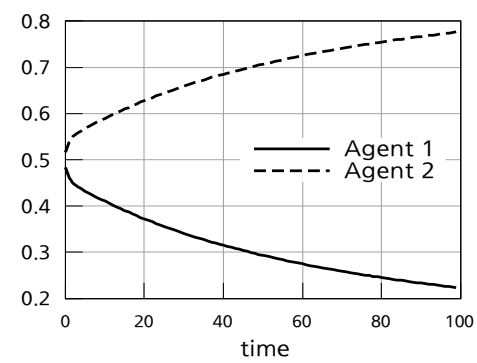

c) Average financial wealth

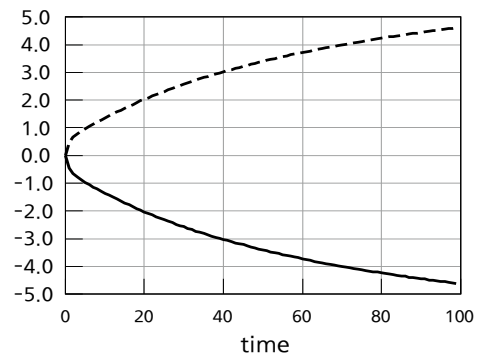

b) Consumption share quantiles

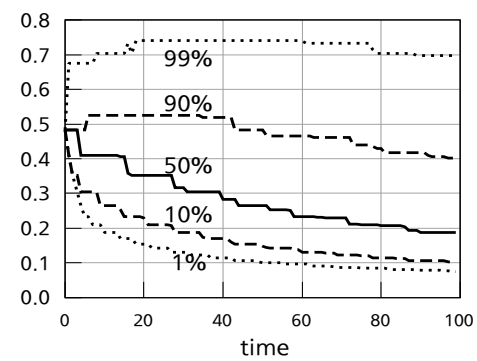

d) Financial wealth quantiles

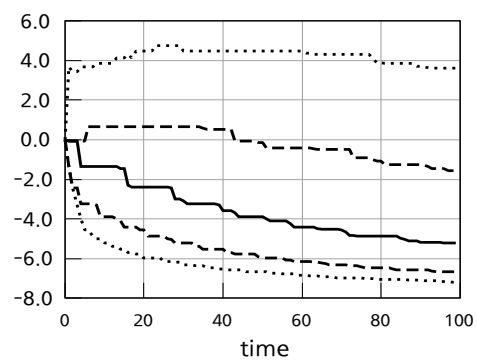


More detail is provided in figure 3, which illustrates four sample paths from the ensemble. The four paths correspond to the 1st, 10th, 90th, and 99th percentiles, respectively, of cross-sectional distribution for agent 2's consumption share in year 100. The top row illustrates paths on which agent 2's bets turn out well. No contractions and many recessions occur on the sample path shown in the upper-left panel. Agent 2 never has to pay out on contraction-state liabilities and frequently collects on recession-state assets. His consumption share ticks upward each time a recession occurs, reflecting the gain in his financial wealth. Similarly, the upper-right panel depicts a sample path with a single contraction and many recessions. He again collects often on recession-state assets and has to pay out only once on contractionstate liabilities. Wealth and consumption tick up each time a recession occurs and decline slightly in the contraction.

Figure 3: Selected sample paths under complete markets

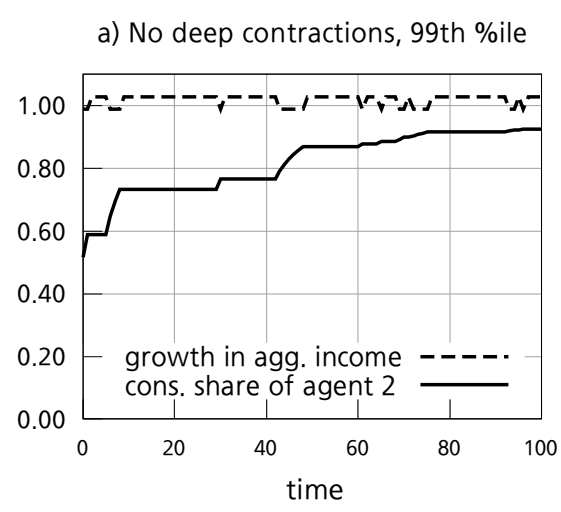

c) Three deep contractions, 10 th $\%$ ile

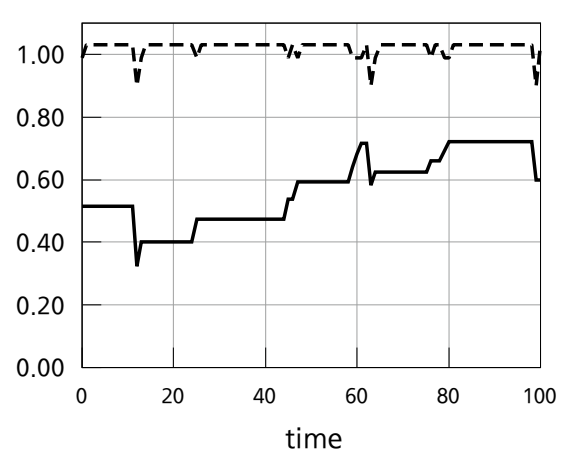

b) One deep contraction, 90th \%ile

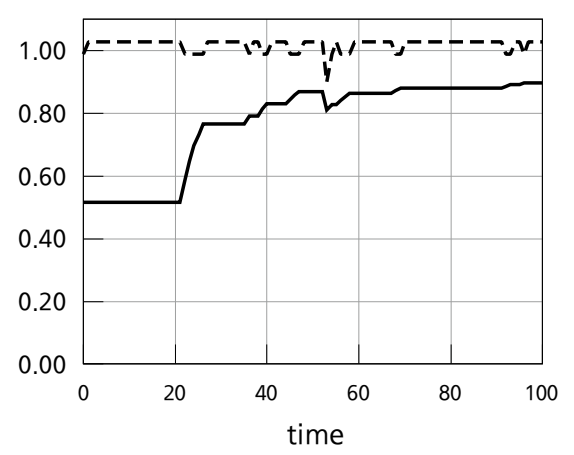

d) Five deep contractions, 1st \%ile

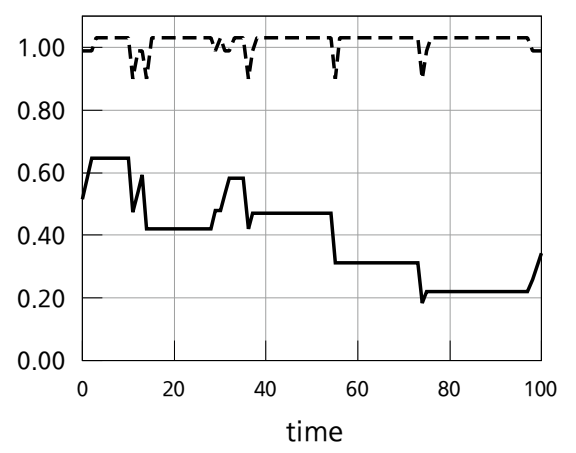


The bottom row illustrates sample paths on which agent 2's bets turn out less well. Fewer recessions and two contractions occur on the sample path depicted in the lower-left panel. Gains in recessions still offset losses in contractions, but just barely. Agent 2's wealth and consumption are only slightly higher at the end of the sample than at the beginning. The lower-right panel portrays a rare sample path with many contractions and few recessions. Agent 2's bets turn out badly in this case, and wealth and consumption share both decline over time.

These results establish that the complete-markets version of the model behaves in essentially the same way as that of Cogley and Sargent (2009). We turn next to our main issue, which is how the evolution of the wealth and consumption distributions differ when markets are incomplete.

\section{A Bond Economy}

There are many ways that markets could be incomplete. In this section, we shut markets for Arrow securities and assume instead that only a risk-free bond is traded. Hence the flow-budget constraint for individual $i$ after history $g^{t}$ becomes

$$
y^{i}\left(g^{t}\right)+b^{i}\left(g^{t-1}\right) \geq c^{i}\left(g^{t}\right)+q_{b}\left(g^{t}\right) b^{i}\left(g^{t}\right)
$$

where $q_{b}\left(g^{t}\right)$ and $b^{i}\left(g^{t}\right)$ represent the price of the bond and the quantity held by consumer $i$, respectively. Individuals can borrow by taking a negative position in the bond that respects a borrowing limit parameterized as

$$
B^{i}\left(g^{t}\right) \equiv B^{i} \cdot y\left(g^{t}\right)
$$

We initially assume that a consumer's debt cannot exceed twice his annual income, a constraint that is quite a bit tighter than the natural debt limit considered in the previous section. Later we examine what happens when the debt limit is relaxed.

In all other respects, the model is identical to the one in sections $\mathbb{I}$ and $\mathbb{I I}$. The only differences are the number of assets traded and the limit on borrowing. 


\section{A recursive formulation}

We solve for a wealth-recursive Markove quilibrium in which the distribution of financial wealth is an endogenous state variable. ${ }^{10)}$ Because the aggregate endowment process is non-stationary, variables must be scaled appropriately. Since the one-period utility function is homothetic, we scale all variables by the current level of aggregate income, using the notation $\hat{x}\left(g^{t}\right)$ to represent $x\left(g^{t}\right) / y\left(g^{t}\right)$. Note that bond position at history $g^{t}$ is chosen at $g^{t-1}$ and so is scaled by $y\left(g^{t-1}\right)$. Utilities are scaled by $\left[y\left(g^{t}\right)\right]^{1-\gamma}$.

Let $V_{b}^{i}(\hat{b}, \hat{w}, n, m, g)$ be the optimal value of agent $i$, normalized by $y^{1-\gamma}$. State variables are the agent's bond position $b$, the distribution of financial assets $\hat{w}=\left(\hat{b}^{1}, \hat{b}^{2}\right)$, the aggregate growth state $g$, and the counters $(n, m)$ that summarize agent 1's beliefs. The value function satisfies the Bellman equation,

$$
V_{b}^{i}(\hat{b}, w, n, m, g)=\max _{\hat{c}, \hat{b}^{\prime}}\left[u(\hat{c})+\beta \sum_{j \in G} V^{i}\left(\hat{b}^{\prime}, w^{\prime}, j, n^{\prime}, m^{\prime}\right) g_{j}^{1-\gamma} \pi^{i}\left(g_{j} \mid g\right)\right]
$$

where the maximization is subject to the budget constraint

$$
\hat{c}+q_{b} \hat{b}^{\prime}=\hat{b} / g+\phi^{i}
$$

and borrowing limit

$$
\hat{b}^{\prime} \geq-B^{i}
$$

Agents take the evolution of the aggregate states as given,

$$
\begin{aligned}
\hat{w}^{\prime} & =\Omega(\hat{w}, n, m, g, j) \\
\left(n^{\prime}, m^{\prime}\right) & =\mathcal{L}(n, m, j)
\end{aligned}
$$

where the function $\mathcal{L}(\cdot)$ summarizes Bayes updating and $\Omega(\cdot)$ is the equilibrium

10) See Kubler and Schmedders (2003) for a discussion of the equilibrium concept. Krusell and Smith (1998) employ the same equilibrium concept. 
wealth-transition map, yet to be determined. Markets clear when $\forall(\hat{w}, n, m, g)$ consumers' optimal policy functions satisfy

$$
\begin{aligned}
\hat{b}^{\prime 1}(\hat{w}, n, m, g)+\hat{b}^{\prime 1}(\hat{w}, n, m, g) & =0 \\
\hat{c}^{1}(\hat{w}, n, m, g)+\hat{c}^{2}(\hat{w}, n, m, g) & =1
\end{aligned}
$$

Let $z$ denote the combined exogenous aggregate state $(n, m, g)$. A wealth-recursive Markove quilibrium is a list of policy functions $\left(\rho_{c}^{i}(\hat{w}, z), \rho_{b}^{i}(\hat{w}, z)\right)_{i=1,2}$, bond price function $q_{b}(\hat{w}, z)$, and a wealth transition map $\Omega(\hat{w}, z)$ such that (i) the functions $\left(\rho_{c}^{i}, \rho_{b}^{i}\right)$ solve problem (30-33) given the price system $q_{b}$; (ii) goods and financial markets clear; and (iii) the wealth-transition map $\Omega(\hat{w}, z)$ is consistent with individual decisions: $\Omega(\hat{w}, z)=\left(\rho_{b}^{1}(\hat{w}, z), \rho_{b}^{2}(\hat{w}, z)\right)$.

When $\gamma \geq 1$, an argument of Duffie et al. (1994) can be adapted to show that

$$
B^{i} \leq \min _{g_{t+1}}\left[g_{t+1} \hat{y}^{i}\left(g^{t+1}\right)\right]
$$

is a sufficient condition for the existence of a wealth-recursive Markov equilibrium. ${ }^{11)}$ This borrowing limit is extremely tight, however, because it guarantees that debt can always be repaid within a single period, implying that debt never exceeds an agent's minimum income. An equilibrium might or might not exist when the debt limit is more lax than this. In what follows, we successfully compute equilibria for weaker debt limits, but we anticipate that the equilibrium would eventually break down as the debt limit is progressively relaxed. It is important to be sensitive to whether an equilibrium exists. An example of Kubler and Polemarchakis (2002) shows that even when an equilibrium does not exist, approximate equilibria that satisfy equilibrium conditions only approximately may exist.

\section{Computing the equilibrium}

We solve for the equilibrium policy and price functions using a projection method.

11) The assumption that $\gamma \geq 1$ is needed to insure that consumption is bounded away from zero. 
For agiven state $z=(n, m, g)$, we use cubic splines to approximate the bond-price map $q_{b}(\hat{b}, z)$, decision rules $\rho_{c}^{1}(\hat{b}, z), \rho_{c}^{2}(\hat{b}, z), \rho_{b}^{1}(\hat{b}, z), \rho_{b}^{2}(\hat{b}, z)$, and Lagrange multipliers on borrowing constraints, $\mu^{1}(\hat{b}, z), \mu^{2}(\hat{b}, z)$. The splines are defined on $[-B, B]$. Our grid has $500 \times 3 \times 20 \times 220=6,600,000$ nodes. The state space for the counter pair $(n, m)$ is such that the probability of reaching the boundary after 500 periods is less then 0.0001 .

Appendix $\mathrm{C}$ describes a number of tests for assessing the accuracy of the approximation. There we demonstrate that the maximum approximation error amounts to less than $\$ 22$ per $\$ 10,000$ of consumption, or $0.14 \%$ of total income. For comparison, the statistical discrepancy in the U.S. NIPA between 1929 and 2010 averaged $0.54 \%$ of total income.

Figure 4: Decision rules and equilibrium price functions. Financial wealth is measured in multiples of the aggregate endowment.

a) Consumption share of agent $1(t=0)$

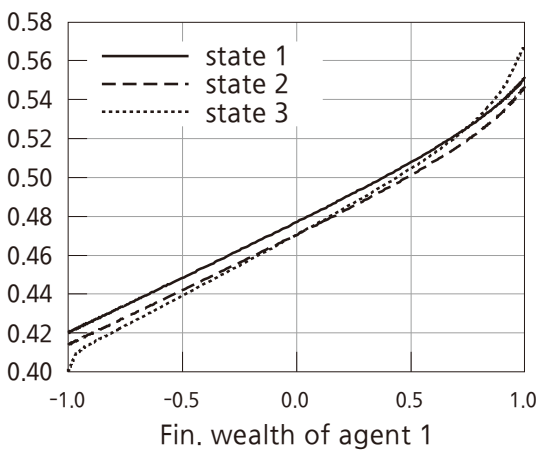

c) Bond price $(t=0)$

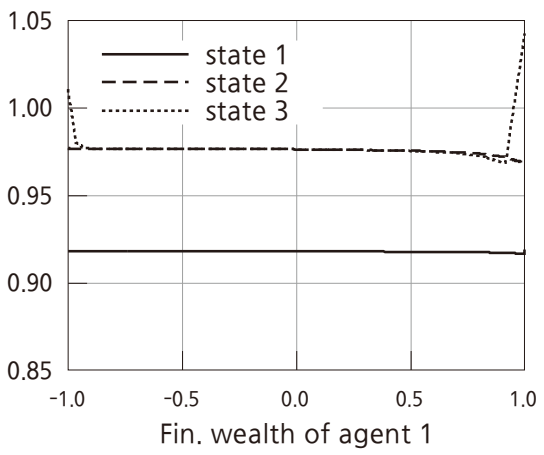

b) Consumption share of agent $1(t=50)$

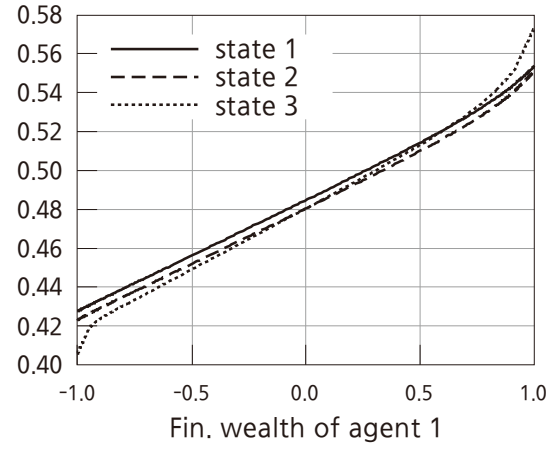

d) Bond price $(t=50)$

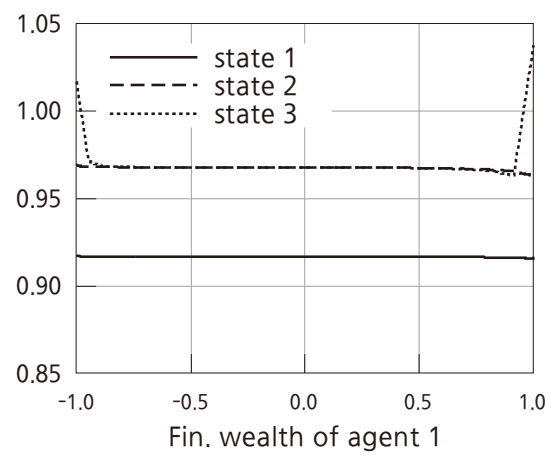


Figure 4 shows decision rules for agent 1 as well as the equilibrium map for bond prices. ${ }^{12)}$ The time-zero plot is based on the sufficient prior counters $(n, m)=$ $(5,5)$, while that for $t=50$ conditions on the median value of the counters in that period, $(n, m)=(6,11)$. A number of salient features emerge. Agent 1's consumption share depends on financial wealth, but it varies little across growth states, being only slightly lower in contractions than in expansions. In addition, consumption policies hardly change as time passes and agent 1 learns. Third, bond prices are higher in contractions and lower in expansions, but away from borrowing constraints they are insensitive to the distribution of financial wealth.

Consumption of Type-1 consumers is lower in recessions because precautionary motives are stronger then. Recall that consumers disagree about recession states. Since recessions are more likely after a recession, pessimism of the less knowledgeable agent 1 drives his consumption and the bond return down. Agent 1's pessimism has a smaller effect on equilibrium quantities in expansions because adverse events are less likely to follow.

\section{Simulation results}

To compare the bond economy with the complete-markets model, we simulate consumption and savings outcomes and calculate equilibrium bond prices for the same endowment paths as in section $\mathbb{I I}$. We initialize the financial wealth distribution at $\left(\hat{b}^{1}, \hat{b}^{2}\right)=(0,0)$. Figures 5-7 portray the results.

The left column of figure 5 depicts ensemble averages for consumption and financial wealth, which are again expressed as proportions of aggregate income. In contrast to the complete-markets model, the less well informed agent 1 accumulates financial wealth in the bond economy, and the better informed agent 2 goes into debt. On average, agent 2's debt reaches approximately 50 percent of aggregate income (100 percent of individual income) after 20 years and approaches his borrowing limit of -1 (200 percent of individual income) after about 80 years. ${ }^{13)}$ Beyond that

12) Consumption and financial wealth are both normalized by dividing by aggregate income.

13) No kink appears in the graph because we average across sample paths, some of which reach the limit 
point, agent 2 rolls over his debt forever.

The main economic force in play is precautionary saving and its effect on the equilibrium real interest rate. Because agent 1 is pessimistic about contractions, his precautionary motives are stronger than they would be in a homogeneous-beliefs rational-expectations version of the model. When markets are complete, Type-1 consumers guard against contractions by purchasing Arrow securities that pay off in that state. They lose wealth on average because those states occur less often than they expect. That market is closed in the bond economy, so now Type-1 consumers guard against contractions by buying risk-free bonds, thus accumulating wealth. ${ }^{14)}$

Figure 5: Wealth and consumption when markets are incomplete. Financial wealth is measured in multiples of the aggregate endowment.

a) Average consumption share

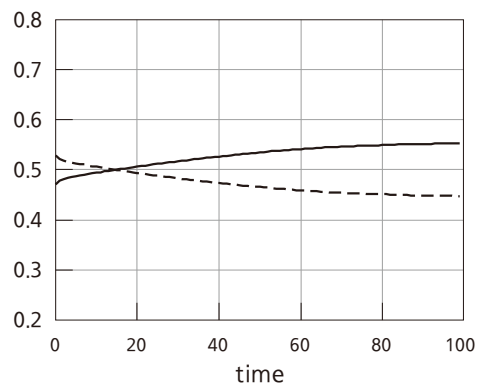

c) Average financial wealth

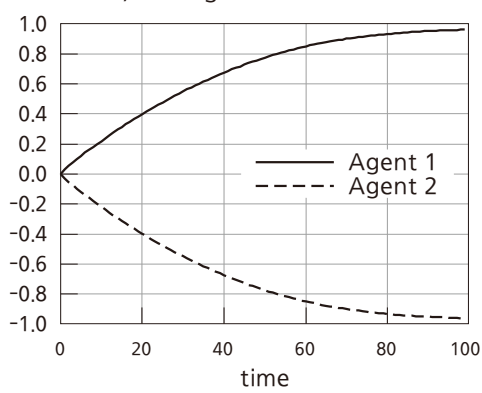

b) Consumption share quantiles

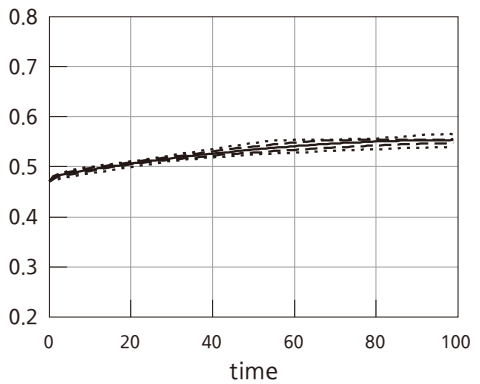

d) Financial wealth quantiles

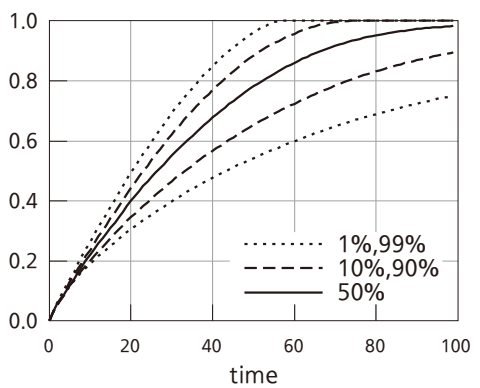

sooner than others.

14) To verify our intuition about precautionary saving, we also examined an economy in which Type-1 agents are initially optimistic. As expected, this reverses the direction in which wealth is transferred. Because Type-1 consumers are less concerned about contractions, their precautionary motives are weaker than under rational expectations. Hence they value bonds less than Type-2 consumers and decumulate wealth along the transition path. 
Figure 6: Average bond price, $q_{b} / q_{b}^{H B}$

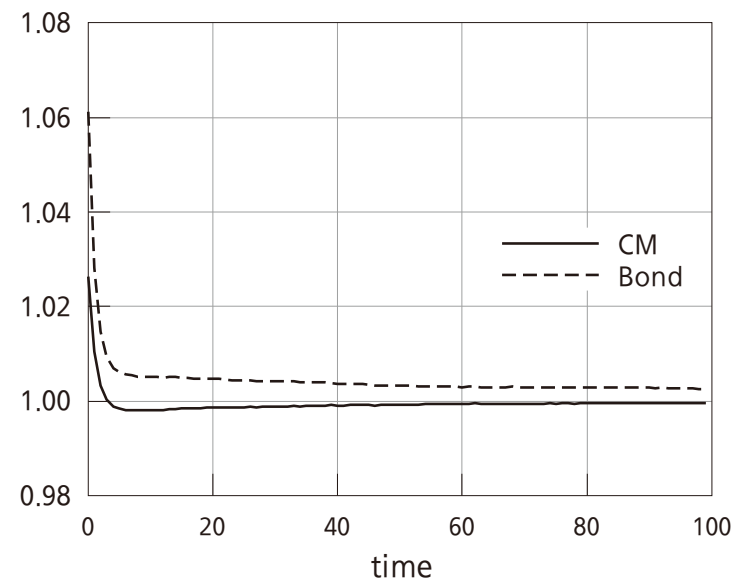

As shown in figure 6, agent 1's attempts to save more initially drive up the equilibrium bond price. Agent 2 is happy to borrow at this low real interest rate in order to transfer consumption from the future to the present. The consumption profile for agent 2 therefore slopes downward, while that of agent 1 slopes upward. ${ }^{15)}$ As agent 1's pessimism dissipates, he engages in less precautionary saving, and the bond price falls. Beliefs eventually converge, and the two agents settle into a homogeneous-beliefs equilibrium with a distribution of wealth permanently favoring agent 1. Thus, the initially less well informed Type-1 agents not only survive, they prosper.

The right column of figure 5 portrays quantiles of the respective cross-samplepath distributions for agent 1 . The distributions of consumption and wealth are more tightly concentrated than under complete markets, and the distribution of consumption shares stays close to that of income shares. This reflects the fact that policy functions for consumption shares are less sensitive to recessions and contractions than in the complete-markets model.

Figure 7 makes the same point, depicting outcomes for the bond-economy on the endowment paths shown in figure 3 . Whereas recessions and contractions induce big jumps in figure 3 , they result in little ticks in figure 7 . This occurs because agent 
2 can no longer bet against contractions or in favor of recessions because no markets exist in which to place those bets. Shutting Arrow-security markets therefore deactivates the main mechanism through which Friedman's (1953) survival hypothesis operates in the complete markets economy of section $\mathbb{I I}$. As a consequence, consumption shares in the bond economy never stray far from income shares, even on endowment paths in the tails of the complete-markets economy.

Figure 7: Selected sample paths when markets are incomplete

a) No deep contractions, 99th \%ile

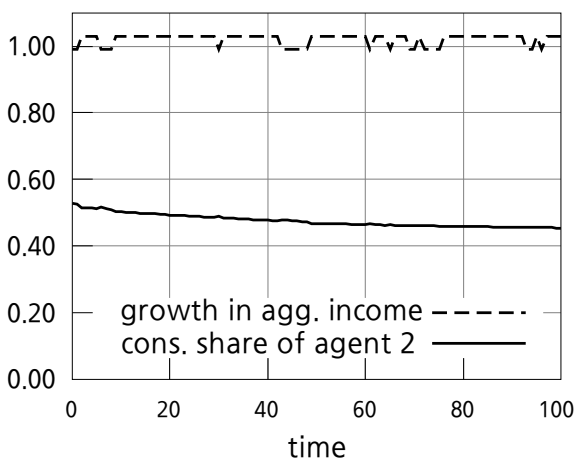

c) Three deep contractions, 10th \%ile

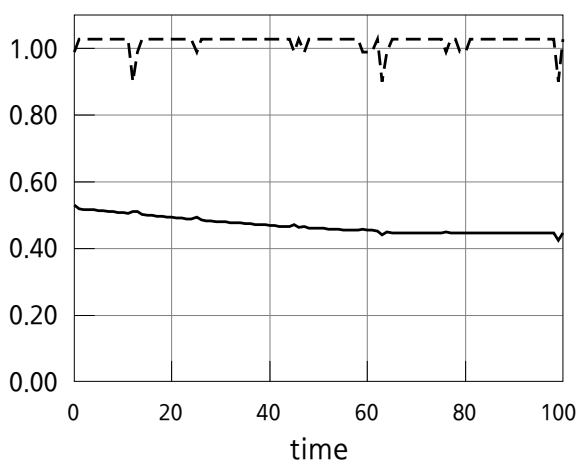

b) One deep contraction, 90th \%ile

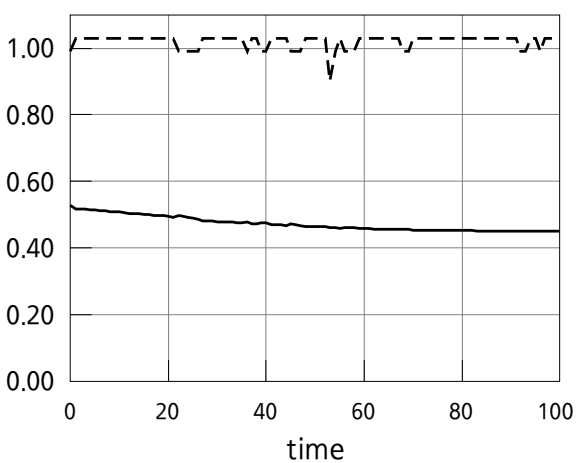

d) Five deep contractions, 1st \%ile

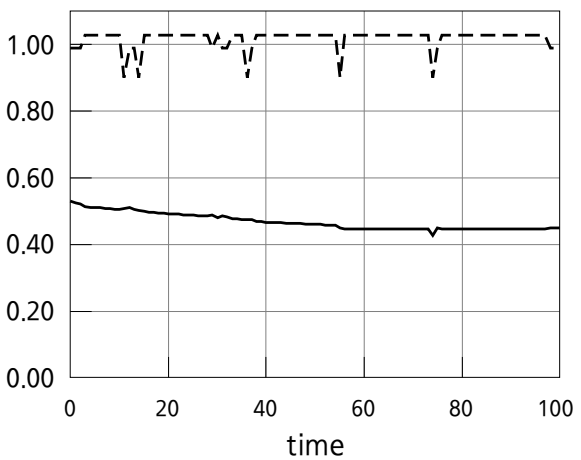

Although precautionary motives are important for understanding the bond economy, they arise here for a different reason than in standard models of incomplete markets (see Heathcote, Storesletten and Violante, 2009). To understand why, rewrite agent 1's welfare function as 


$$
\sum_{t=0}^{\infty} \sum_{g^{t}} \beta^{t} \frac{\pi^{1}\left(g^{t}\right)}{\pi^{2}\left(g^{t}\right)} \pi^{2}\left(g^{t}\right) u\left(c_{t}^{1}\left(g^{t}\right)\right)=E^{2}\left[\sum_{t=0}^{\infty} \beta^{t} \frac{\pi^{1}\left(g^{t}\right)}{\pi^{2}\left(g^{t}\right)} u\left(c_{t}^{1}\left(g^{t}\right)\right)\right]
$$

It follows that our model is equivalent to one in which agents share the same beliefs of agent 2 but in which agent 1 is hit by a preference shock $\pi^{1}\left(g^{t}\right) / \pi^{2}\left(g^{t}\right)$.

If beliefs were homogenous, these "preference shocks" would be absent, agents would have no reason to trade, and consumption would always equal income. In this case, income variation would enter Euler equations only through marginal utility, and only the degree of risk aversion would affect precautionary savings.

Figure 8: Consumption and wealth dynamics of Type-1 agent with different degree of risk aversion. Financial wealth is measured in multiples of the aggregate endowment.

a) Average consumption share

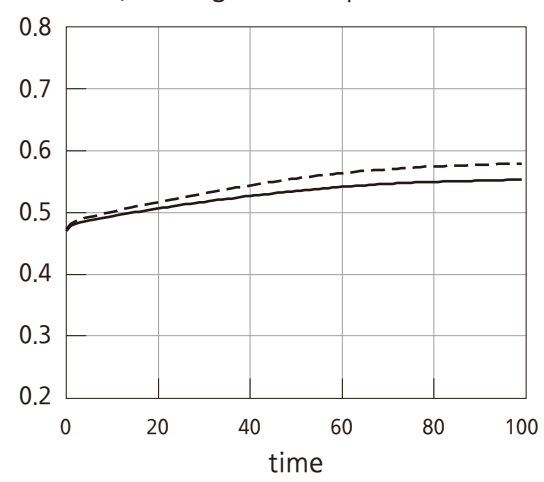

b) Average financial wealth

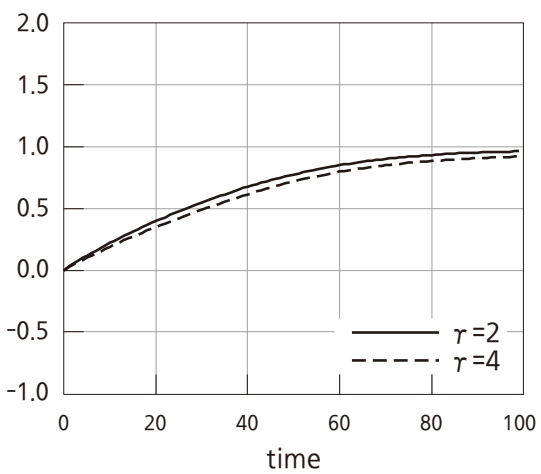

Figure 8 illustrates how the degree of risk aversion affects outcomes when precautionary motives arise partly from heterogeneity in beliefs. The figure portrays average consumption and financial wealth for agent 1 for two economies, one in which the coefficient of relative risk aversion $\gamma=2$ and another in which $\gamma=4$. Consumption and financial wealth dynamics change little when risk-aversion increases. Importantly, unlike the case with idiosyncratic income risk, financial wealth decreases at a slower pace when risk-aversion is high. This happens because higher risk aversion dampens the increase in the bond price, making it less attractive for Type-2 agents to borrow. 


\section{Altering the debt limits}

According to a conventional wisdom, market incompleteness affects allocations less because of absence of spanning and more because debt limits are typically tighter than the natural debt limit. In our model, however, absence of spanning seems crucial because this is what prevents agent 2 from exploiting the pessimism of agent 1. In this subsection, we try to disentangle the effects of differences in debt limits versus absence of spanning.

We begin by relaxing the debt limit in the bond economy, moving it toward the natural borrowing limit of the complete-markets model. If this were what really mattered, outcomes would move toward those under complete markets. Figure 9 plots agent 1's average consumption share and financial wealth in bond economies with debt limits of $B=1$ and $B=4$, respectively. It shows that relaxing the debt limit actually moves outcomes farther away from the complete-markets allocation. Type-1 consumers accumulate wealth even faster as the effect of a binding borrowing limit is not felt during the first 100 years.

Next we examine what happens under complete markets when the natural borrowing limit is replaced by the ad hoc debt limit of the bond economy. Figure 10 shows that wealth is transferred in the same direction as in the baseline completemarkets model and opposite to that of the bond economy. The primary consequence of the tighter ad hoc borrowing limit is that the average consumption share for agent 1 is bounded away from zero. This occurs because agent 1 can no longer pledge his entire future income stream for repayment of debt.

Absence of spanning therefore seems to be the central force accounting for differences between complete-market outcomes and those in the bond economy. Differences in the debt limit matter quantitatively, but less so qualitatively. 
Figure 9: Consumption and wealth dynamics of Type-1 agent in the bond economy with different debt limits. Financial wealth is measured in multiples of the aggregate endowment.

a) Average consumption share

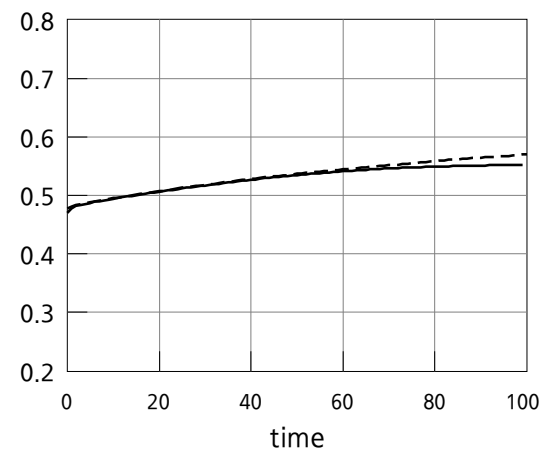

b) Average financial wealth

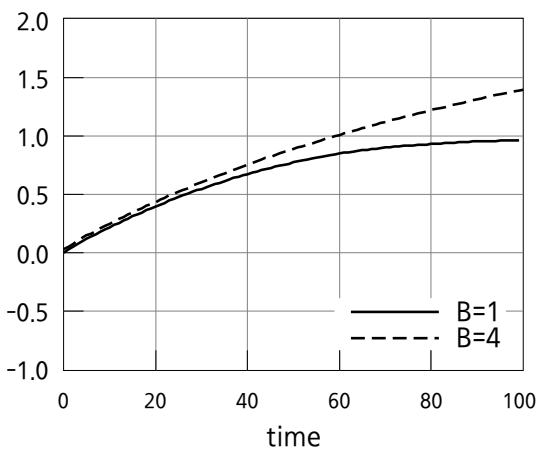

Figure 10: Consumption and wealth dynamics of Type-1 agent in the complete markets economy with different debt limits. Financial wealth is measured in multiples of the aggregate endowment.

a) Average consumption share

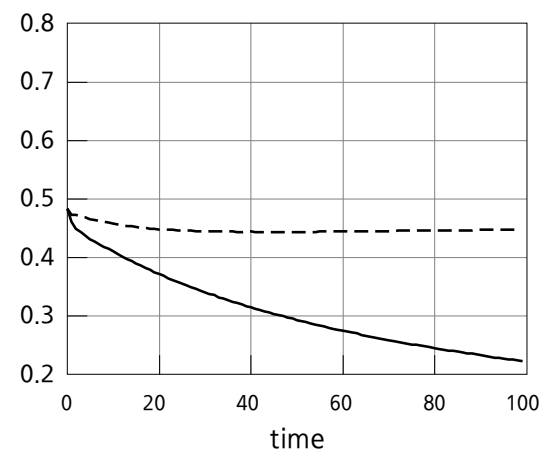

b) Average financial wealth

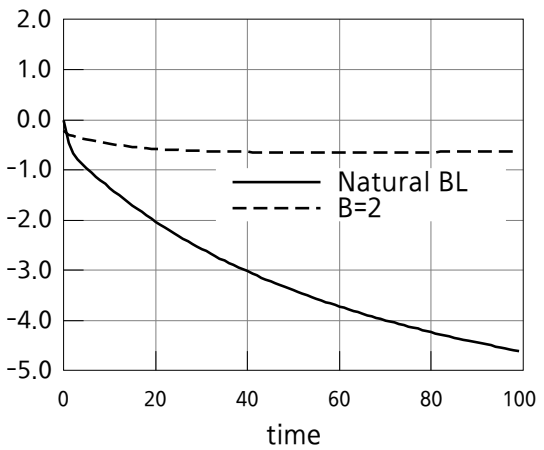

\section{A dogmatic-beliefs economy}

To highlight the role of learning, we examine a heterogeneous-beliefs economy in which the pessimistic agent never learns. Since the pessimism of Type-1 con- 
sumers now remains constant, they accumulate wealth faster relative to consumers who update their beliefs. Figure 11 confirms this intuition.

Figure 11: Consumption and wealth dynamics of Type-1 agent in the bond economy under different learning strategies. Financial wealth is measured in multiples of the aggregate endowment.

a) Average consumption share

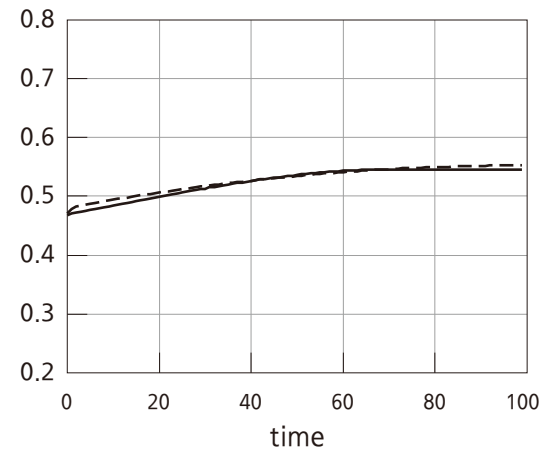

b) Average financial wealth

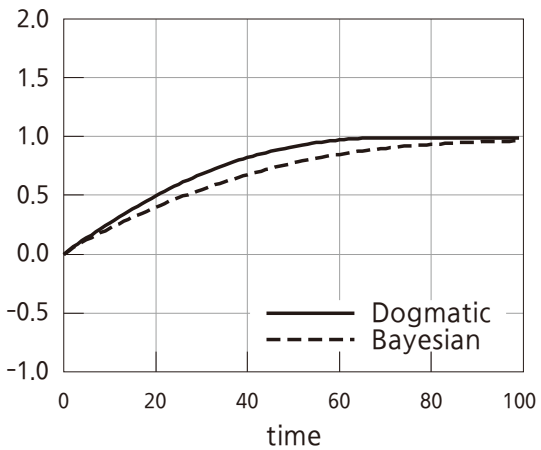

\section{Intermediate economies}

To gain further insight into the influence of market structure on the balance between precautionary and speculative forces, we examine economies in which two assets are traded, a risk-free real bond and a single Arrow security. In these economies, consumers can synthesize a portfolio of Arrow securities for two states, leaving them one asset short of complete markets. Our objective is to explore how opening or closing particular asset markets affects opportunities for speculation, channels for precautionary saving, and the distribution of wealth. ${ }^{16)}$

For economy $j \in\{1,2,3\}$, a risk-free bond is traded along with an Arrow security paying off in state $j$. Markets for other Arrow securities are closed. Agent $i$ 's flow

16) An appendix providing a detailed analysis of these intermediate economies can be found online at https:// files.nyu.edu/tc60/public. 
budget constraint therefore is:

$$
c^{i}\left(g^{t}\right)+q_{b}\left(g^{t}\right) b^{i}\left(g^{t}\right)+q_{j}\left(g^{t}\right) s_{j}^{i}\left(g^{t}\right)=e^{i}\left(g^{t}\right)+b^{i}\left(g^{t-1}\right)+s_{j}^{i}\left(g^{t-1}\right) \cdot 1_{j}\left(g_{t}\right)
$$

where $s_{j}^{i}\left(g^{t}\right)$ represents agent $i$ 's positions in Arrow security $j$ and $q_{j}\left(g^{t}\right)$ is its price. Consumption and security purchases cannot exceed the sum of agent $i$ 's current endowment $e^{i}\left(g^{t}\right)$ plus financial wealth brought into the period, $b^{i}\left(g^{t-1}\right)+s_{j}^{i}\left(g^{t-1}\right) \cdot 1_{j}\left(g_{t}\right)$, where $1_{j}\left(g_{t}\right)$ is an indicator function that equals 1 when $g_{t}=j$ and is zero otherwise.

We again assume that agents can take a negative position in risk-free bonds up to a limit of twice their annual income, $b^{i}\left(g^{t}\right) \geq-B y^{i}\left(g^{t}\right), B=2$. Positions in the traded Arrow security must also be restricted, and we assume that consumers can borrow by selling the Arrow security up to a limit of one annual income:

$$
s_{j}^{i}\left(g^{t}\right) \geq-S y^{i}\left(g^{t}\right), \quad S=1
$$

All other aspects of the model are identical to those presented above. As before, we restrict attention to wealth-recursive competitive equilibria in which individual decisions and the price system are functions of the wealth distribution, the current aggregate state $g^{t}$, and sufficient statistics for agent 1's beliefs.

We simulate the three intermediate economies and compare outcomes with those in the complete-markets and bond-only economies. Figure 12 summarizes our results, showing how the average share of wealth for Type-1 consumers depends on market structure. As expected, the complete-markets and the bond economies represent two extremes. Two of the three intermediate economies - those in which markets for expansion- or mild-recession-state securities are open - broadly resemble the bond economy, while the third - that in which a deep-contraction security is traded - is qualitatively more like the complete-markets economy. In the first two, precautionary motives dominate, and Type-1 consumers accumulate wealth. Speculative forces return to the fore in the third economy, and Type-1 consumers lose wealth on average because they make regrettable investments in the deep contraction security. 
Intuition for these outcomes can be developed by thinking about channels for precautionary saving. Since the learning agent is pessimistic, he wants to buy assets that pay off in deep contractions. In economies 1 and 2, a positive payoff in deep contractions can be achieved only by holding the risk-free bond. Type-1 consumers therefore purchase the bond, driving its price above its full-information value and inducing Type-2 consumers to sell. To leverage their position in the risk-free bond, Type-1 consumers sell the available Arrow security. Relative to the bond-only economy, however, their purchases of the risk-free bond are smaller, and they must pay out on average on their Arrow security obligations. Both factors cause wealth to accumulate more slowly and to asymptote at a lower level than in the bond economy. But the fact that precautionary savings must be channeled into the risk- free bond promotes wealth accumulation for Type-1 consumers.

Figure 12: Average wealth share of the less-informed consumer under different financial market structures

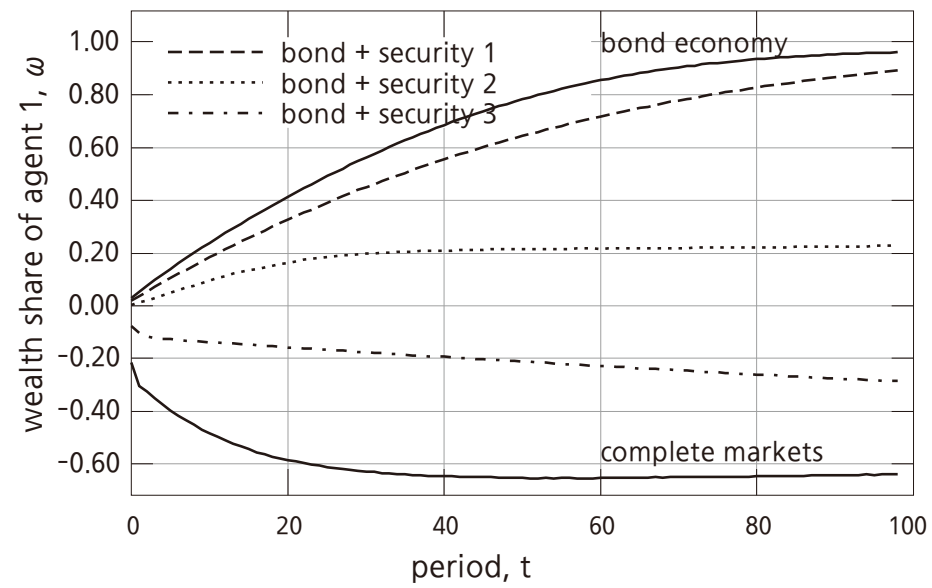

In the third economy, consumers can trade a risk-free bond and an Arrow security paying off in deep contractions. Since the learning agent can now insure against deep contractions by buying an Arrow security that pays off in that state, precautionary savings need no longer be channeled into the risk-free bond. On the contrary, Type-1 consumers now sell the risk-free bond in order to afford larger pur- 
chases of the Arrow security. Type-1 consumers therefore sell safe assets in order to leverage their purchases of the risky asset. Because they over-estimate the probability of deep contractions and underestimate the probability of mild recessions, they suffer financial losses more often and reap gains less often than expected, thus losing wealth on average. In this respect, economy 3 resembles a complete-markets economy. The rate at which wealth is transferred is slower, however, simply because fewer markets are open and fewer speculative opportunities exist. Opening a market for a deep-contraction security therefore changes wealth dynamics dramatically.

\section{Related literature}

We are not the first to show that Blume and Easley's (2006) complete-market survival result can be reversed when markets are incomplete. Blume and Easley provided an example themselves. In their example, agents who are over-optimistic about an asset's payoff survive because they save and invest more. Our mechanism is similar in that agents have heterogeneous beliefs about the economic fundamentals that determine asset prices, and disagreement about those fundamentals motivate less well informed agents to save more. In our model, however, the increase in savings occurs because of precautionary motives rather than a desire to exploit higher expected returns.

Guerdjikova and Scuibba (2010) and Borovicka (2011) also provide examples in which less well informed consumers save their way to survival. They examine complete-market economies in which consumers have ambiguity-averse and recursive (Epstein-Zin) preferences, respectively. As in our model, precautionary behavior play a central role, but Guerdjikova and Scuibba and Borovicka strengthen precautionary motives by altering Blume and Easley's preference specification, whereas we alter the market structure.

The literature explores other routes to survival as well. For instance, Sandroni (2005) studies a two-period model in which only a subset of Arrow securities is traded. He shows that an agent who is closest to the truth in the space of "tradeable states" will accumulate wealth. Agents with mistaken beliefs about states in which no asset pays 
out need not be driven to extinction. In our bond economy, Type-1 consumers survive despite having mistaken beliefs about states in which an asset pays out, and Type-2 agents are driven to debt limits despite having correct beliefs about all states.

Coury and Sciubba (2010) demonstrate that impatient traders with incorrect beliefs can survive and influence prices. Roughly speaking, they show how differences in discount rates can be calibrated to offset mistaken beliefs (see our expression, 35). We assume identical preferences and focus solely on differences in beliefs.

Beker and Chattopadhyay (2010) study a family of economies closely related to ours with two agents, incomplete markets, infinite horizons, and "implicit debt constraints" defined by agents' budget constraints. ${ }^{17)}$ Importantly, they assume that borrowing limits never bind in equilibrium. For this class of economies, they prove a number of interesting theorems about survival, and they provide an example in which an agent with correct beliefs eventually has zero consumption with probability one. In contrast, we invoke debt limits tighter than the natural borrowing limit in order to ensure existence of a wealth-recursive equilibrium, and we find that they do bind in equilibrium. Whether Beker and Chattopadhyay's theorems can be extended to economies with binding debt limits is an open question.18)

When debt limits tighter than the natural borrowing limit bind in equilibrium, no consumer can pledge to repay the entire present value of his endowment stream. This makes survival automatic because a fraction of income is always available to support positive consumption. Thus, we focus less on survival per se and more on how the wealth distribution evolves.

A similar comment applies when borrowers can default, as in Tsyrennikov (2011) or Cao (2011). Tsyrennikov studies a model in which agents are allowed to renege on their obligations, as in Alvarez and Jermann (2000). Because agents face endogenous solvency constraints, financial markets are incomplete, yet all agents survive. Similarly, Cao analyzes an environment with collateral constraints a la Geanakoplos and Zame (2002).

17) Beker and Espino (2011) use a closely-related model to explain asset-pricing anomalies.

18) When markets are complete, the natural borrowing limits never bind in equilibrium. But the argument in Tsyrennikov (2012) can be used to prove that any limits that are tighter must bind when agents have heterogeneous beliefs. 


\section{Concluding remarks}

In future research, we plan to investigate the welfare consequences of closing markets. For a Pareto criterion that respects agents' preferences, which means that their beliefs are taken as given, equilibrium allocations in the complete markets economy are Pareto optimal, while those in the bond and intermediate economies are not. But for a Pareto criterion that disrespects agents' preferences by using beliefs different than theirs to evaluate outcomes, incomplete-markets economies can dominate the complete-markets outcome. For instance, Blume et al. (2012) describe what they interpret as a Rawlsian welfare criteria that evaluates outcomes behind a time -1 veil of ignorance about belief types that nature assigns randomly just before the start of time 0. According to that criterion, closing markets can be superior because it prevents the immiseration of the least well off type. 


\section{Appendix A. A recursive formulation for the complete- markets model}

Because the aggregate endowment is non-stationary, we begin by scaling variables appropriately. Since the one-period utility function is homothetic, we scale all variables by the current level of aggregate income. We use $\hat{x}\left(g^{t}\right)$ to denote $x\left(g^{t}\right) / y\left(g^{t}\right)$. The bond position at history $g^{t}$ is chosen at $g^{t-1}$ and so is scaled by $y\left(g^{t-1}\right)$. Utilities are scaled by $y\left(g^{t}\right)^{1-\gamma}$.

We solve for a wealth-recursive Markov equilibrium. In a wealth-recursive Markov equilibrium, the distribution of financial wealth $\hat{w}=\left(\hat{a}^{1}, \hat{a}^{2}\right)$ is an endogenous state variable. The other state variables for individual $i$ are his own financial assets $\hat{a}^{i}$, the current aggregate growth state $g$, and the counters $m, n$ that are sufficient statistics for summarizing agent 1 's beliefs.

Let $V_{c m}^{i}(\hat{a}, \hat{w}, n, m, g)$ be the optimal value of individual $i$, normalized by $y^{1-\gamma}$. This value function must satisfy the following Bellman equation,

$$
V_{c m}^{i}(\hat{a}, \hat{w}, n, m, g)=\max _{\hat{c}, \hat{a}_{j}^{\prime}}\left[u(\hat{c})+\beta \sum_{j \in G} V_{c m}^{i}\left(\hat{a}_{j}^{\prime}, \hat{w}^{\prime}, g_{j}, n^{\prime}, m^{\prime}\right) g_{j}^{1-\gamma} \pi^{i}\left(g_{j} \mid g\right)\right]
$$

where expectations are taken with respect to agent $i$ 's predictive distribution, $\pi^{i}\left(g_{j} \mid g\right)$. The maximization is subject to the budget constraint,

$$
\hat{c}+\sum_{j \in G} Q_{j}(\hat{w}, n, m, g) g_{j} \hat{a}_{j}^{\prime}=\hat{a}+\phi^{i}
$$

and the natural borrowing limit,

$$
\hat{a}_{j}^{\prime} \geq-\hat{B}^{i}\left(\hat{w}^{\prime}, n^{\prime}, m^{\prime}, g_{j}\right)
$$

The borrowing limit can be computed recursively by iterating on

$$
\widehat{B}^{i}(\hat{w}, n, m, g)=\phi^{i}+\sum_{j \in G} Q_{j}(\hat{w}, n, m, g) \widehat{B}^{i}\left(\widehat{w}^{\prime}, g_{j}, n^{\prime}, m^{\prime}\right)
$$


Agents take the evolution of aggregate states as given, including those for aggregate financial wealth and the counters,

$$
\begin{aligned}
\widehat{w}^{\prime} & =\Omega\left(\hat{w}, n, m, g, g^{\prime}\right) \\
\left(n^{\prime}, m^{\prime}\right) & =\mathcal{L}\left(n, m, g^{\prime}\right)
\end{aligned}
$$

The function $\mathcal{L}$ is given in equation (9), and the function $\Omega$ is the part of the equilibrium map, which is yet to be computed.

Markets clear when

$$
\begin{aligned}
& \hat{a}_{j}^{1 \prime}(\hat{w}, n, m, g)+\hat{a}_{j}^{2 \prime}(\hat{w}, n, m, g)=0, \quad \forall j \in G \\
& \hat{c}^{1}(\hat{w}, n, m, g)+\hat{c}^{2}(\hat{w}, n, m, g)=1
\end{aligned}
$$

for all $\hat{w}, n, m, g$.

\section{Appendix B. How pessimistic is the prior?}

To assess whether the assumed degree of pessimism is plausible, we consider whether consumers could easily distinguish it statistically from the beliefs of Type- 2 consumers based on a finite data sample. Let $M_{i}$ denote the prior probability model of types $i=1,2$. Following Hansen and Sargent (2008), we measure a consumer's ability to distinguish models by the detection-error probability. Assuming prior weights of $1 / 2$ on each model, the detection-error probability is

$$
\operatorname{dep}=0.5\left[\operatorname{prob}\left(\mathcal{L}_{2}(X)>\mathscr{L}_{1}(X) \mid M_{1}\right)+\operatorname{prob}\left(\mathscr{L}_{1}(X)>\mathscr{L}_{1}(X) \mid M_{2}\right)\right] \in[0,0.5]
$$

where $\mathcal{L}_{i}(X)$ is the likelihood of sample $X$ evaluated using model $M_{i}$. The two models are easy to distinguish when the detection-error probability is close to zero. Using 100,000 simulated samples of length $T=50$ years, we obtain $\operatorname{dep}=12.8 \%$, a figure comparable to those used for calibrating uncertainty aversion in models of robustness. 


\section{Appendix C. Testing the accuracy of the approximation for the bond economy}

The solution consists of the consumption $\rho_{c}^{i}(\hat{b}, n, m, s)$ and the bond investment $\rho_{b}^{i}(\hat{b}, n, m, s)$ policy functions, the Lagrange multipliers associated with borrowing limits $\rho_{\mu}^{i}(\hat{b}, n, m, s)$ and the bond price function $q_{b}(\hat{b}, n, m, s)$. We solve for the policy functions iteratively using the system of equilibrium conditions. The stopping criterion is that the sup distance between consecutive policy function updates is less than $e_{\rho}=10^{-5}$. Decreasing this threshold improves accuracy only marginally. ${ }^{19)}$

We verify the computed solution on a grid that is 5 times denser than the one used to compute policy functions. Verification procedure consists of computing the following errors:

$$
\begin{aligned}
& e_{1}(\hat{b}, n, m, s)=1-\frac{1}{\rho_{c}^{1}(\hat{b}, n, m, s)}\left[\frac{q_{b}(\hat{b}, n, m, s)}{E\left[\left(\rho_{c}^{1}(\hat{b}, n, m, s) g(s)\right)^{-\gamma}\right]+\rho_{\mu}^{1}(\hat{b}, n, m, s)}\right]^{1 / \gamma} \\
& e_{2}(\hat{b}, n, m, s)=1-\frac{1}{\rho_{c}^{1}(\hat{b}, n, m, s)}\left[\frac{q_{b}(\hat{b}, n, m, s)}{E\left[\left(\rho_{c}^{2}(\hat{b}, n, m, s) g(s)\right)^{-\gamma}\right]+\rho_{\mu}^{2}(\hat{b}, n, m, s)}\right]^{1 / \gamma} \\
& e_{3}(\hat{b}, n, m, s)=1-\frac{1}{\rho_{c}^{1}(\hat{b}, n, m, s)}\left[0.5+\hat{b}-q_{b}(\hat{b}, n, m, s) \rho_{b}^{1}(\hat{b}, n, m, s)\right]
\end{aligned}
$$

The errors answer the following question: "what fraction should be added or subtracted from an agent's consumption so that the respective equilibrium condition holds exactly?" The first two equations are the consumption Euler equations for agent 1 and 2 respectively. The third equation is the budget constraint of agent 1. The feasibility constraint is imposed on the solution; so, the budget constraint of agent 2 holds exactly.

The "free parameter" in the numerical analysis is the number of grid points for the bond position. Starting from 50, we increase the number of grid points for the

19) This means that approximation errors begin to dominate numerical errors. 
bond position until a sufficient level of accuracy is achieved. With 500 grid points the errors are smaller than $0.22 \%$ of the average consumption. ${ }^{20)}$ For comparison the statistical discrepancy in the U.S. NIA between 1929 and 2010 averaged at $0.54 \%$ of the total income. ${ }^{21)}$ Errors are larger for higher levels of risk-aversion but stay below $0.35 \%$ of individual consumption as long as $\gamma \leq 5$ (holding the number of grid points at 500).

Figure 13 plots maximal errors (over all possible pairs of counters) for each $\left(b^{1}, s\right)$ pair for $\gamma=2$ and 500 grid points. These errors are largest when $g=3$ which is expected.

We also conduct another test of solution accuracy. The error in equilibrium conditions for the solution with 100 grid points is $1.13 \%$ of consumption; about 5 times that of the 500-grid-point solution. We ask: "how different are simulated paths for solutions with 100 and 500 grid points?" The test path that we chose is a deterministic repetition of the sequence $1,1,1,1,1,2,2,2,2,3$. In this path states 2 and 3 are over-represented relative to the true measure. It turns out (see figure 14) that, even though differences exist, paths do not diverge and the difference stays bounded.

\section{Appendix D. A two-period example}

Consider the following two-period setup. In period 0, aggregate income is 1 . In period 1 , it is $e_{l}>0$ with probability $\pi_{l}$ and $e_{h}>e_{l}$ with complementary probability. Each agent receives half of aggregate income. Agent 2 has correct beliefs, and agent 1 is pessimistic. He assigns probability $\pi_{l}+d, d \in\left[0,1-\pi_{l}\right]$ to the low endowment state.

Agents rank a consumption stream $\left(c_{0}^{i}, c_{1 l}^{i}, c_{1 h}^{i}\right)$ according to:

$$
u\left(c_{0}^{i}\right)+\pi_{l}^{i} u\left(c_{1 l}^{i}\right)+\pi_{h}^{i} u\left(c_{1 h}^{i}\right)
$$

20) This amounts to $22 \$$ for every $10,000 \$$ of consumption.

21) Model errors when normalized by the total income are less than $0.14 \%$. 
where $u$ is a strictly increasing and strictly concave function.

Agents trade only a risk-free bond. Clearly, when $d=0$, the competitive equilibrium allocation is autarkic. How does competitive equilibrium depend on $d$ ?

Let us analyze the bond-demand function of agent $i$ for a given price $q_{b}$.

Figure 13: Bond economy: off the grid errors

a) Equation $1, s=1$

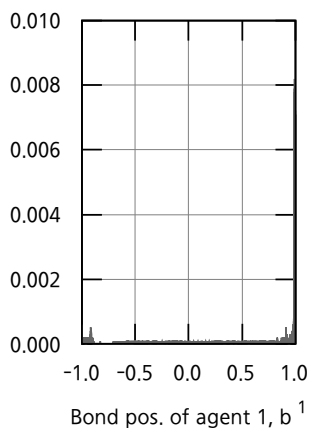

d) Equation 1, s=2

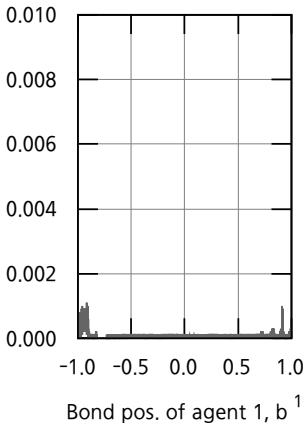

g) Equation 1, s=3

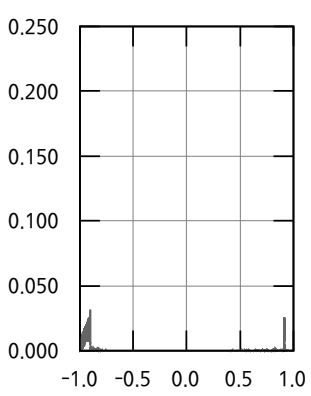

b) Equation 2, s=1

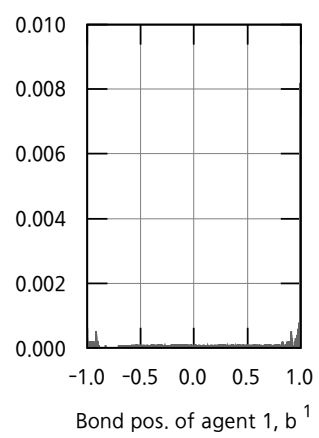

e) Equation 2, s=2

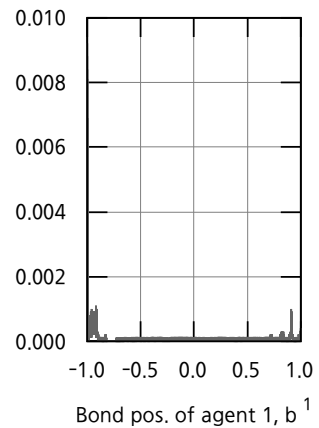

h) Equation 2, s=3

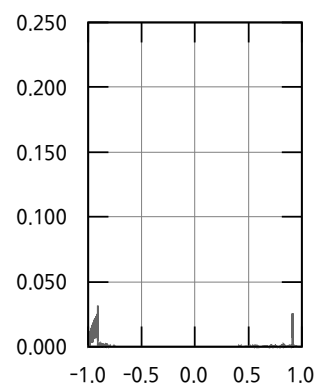

c) Equation 3, s=

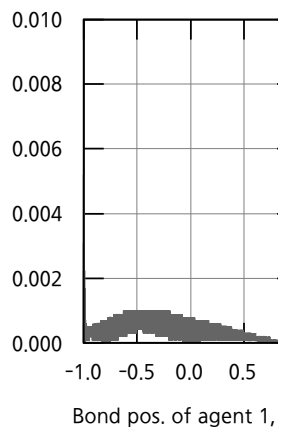

f) Equation 3, s=

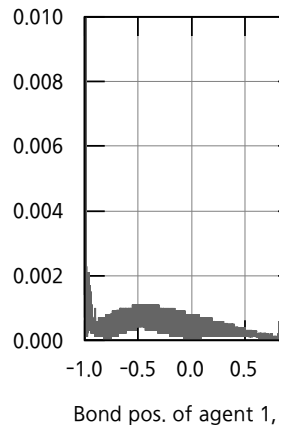

i) Equation 3, s=

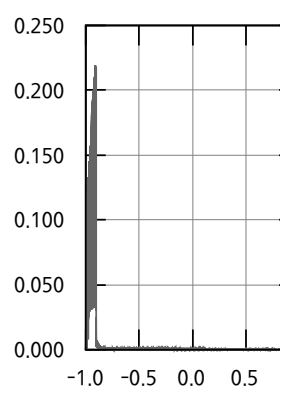


Figure 14: Comparing solutions with different degree of accuracy

a) Bond position, $b^{1}$

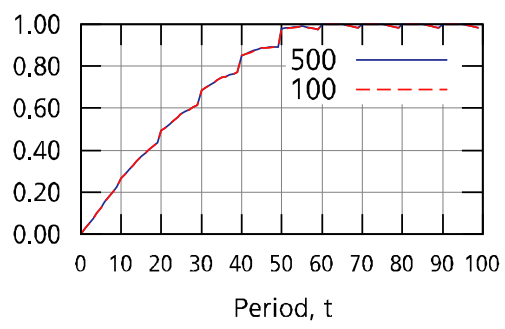

c) Bond price, $\mathrm{q}_{\mathrm{b}}$

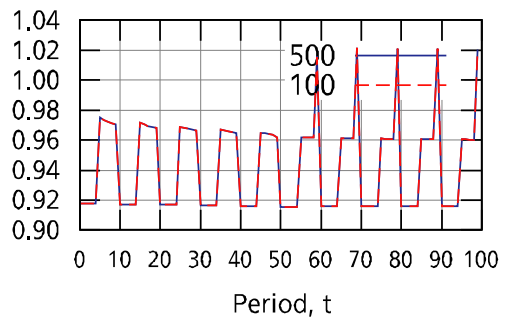

e) Consumption, $c^{1}$

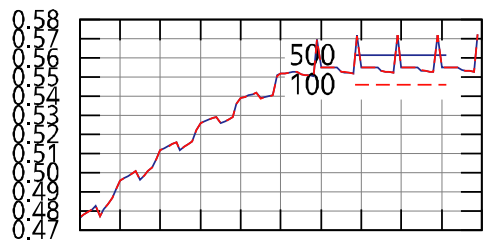

$\begin{array}{lllllllllll}0 & 10 & 20 & 30 & 40 & 50 & 60 & 70 & 80 & 90 & 100\end{array}$ b) Bond position paths difference, $x^{\prime}$

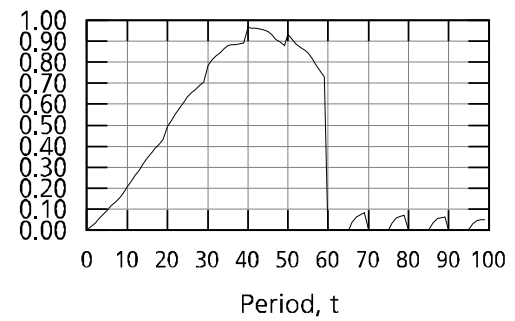

d) Bond price paths difference, $\times 10$

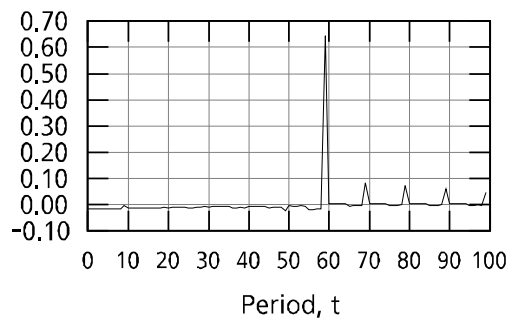

f) Consumption paths difference, $x 1$

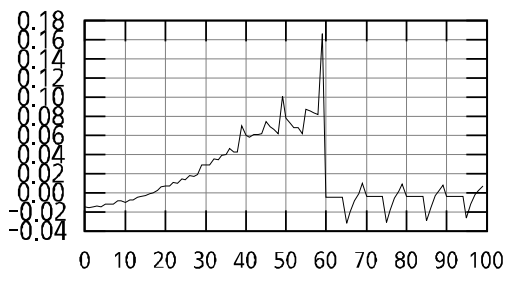

His consumption Euler equation is

$$
q_{b} u^{\prime}\left(1 / 2-q_{b} b^{i}\right)=\sum_{s \in\{l, h\}} \pi_{s}^{i} u^{\prime}\left(e_{s} / 2+b^{i}\right)
$$

For a fixed $q_{b}$, how does $b^{1}$ change with $d$ ? It is easy to show that $\partial b^{1}\left(d, q_{b}\right) / \partial d>0$. Since $b^{2}\left(q_{b}\right)=b^{1}\left(0, q_{b}\right)$, we must have $b^{1}\left(d, q_{b}\right)>b^{2}\left(q_{b}\right), \forall q_{b}, d>0$. Then the bond-market clearing condition implies $b^{1}\left(d, q_{b}^{*}\right)=-b^{2}\left(q_{b}^{*}\right)>0$, where $q_{b}^{*}$ is the equilibrium bond price. This, in turn, implies that $c_{0}^{1}<c_{0}^{2}$ and $c_{1 s}^{1}>c_{1 s}^{2}, s \in\{l, h\}$. Finally, using the consumption Euler-equation again, we can 
show that the bond price must be higher than in the homogenous beliefs case. Using strict concavity of $u$, we get

$$
q_{b}=\frac{E^{2}\left[u^{\prime}\left(e_{s} / 2+b^{2}\right)\right]}{u^{\prime}\left(1 / 2-q_{b} b^{2}\right)}>\frac{E^{2}\left[u^{\prime}\left(e_{s} / 2\right)\right]}{u^{\prime}(1 / 2)}
$$

The term on the right side equals the equilibrium bond price when beliefs are homogeneous. This proves the following claim.

In the two-period economy, relative to the competitive equilibrium with homogeneous beliefs, the pessimistic agent holds a larger position in bonds and consumes less in period 0 and more in period 1. In addition, the equilibrium bond price is higher. 


\section{Appendix E. Model solution}

Figure 15: Decision rules and equilibrium price functions

$c(b, n, m=90, s=1)$

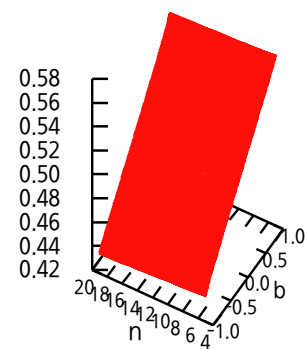

$b(b, n, m=90, s=1)$

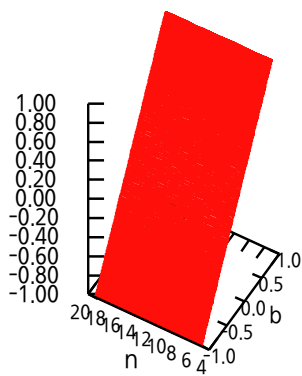

$q(b, n, m=90, s=1)$

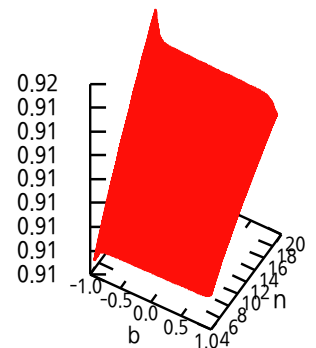

$c(b, n, m=90, s=2)$

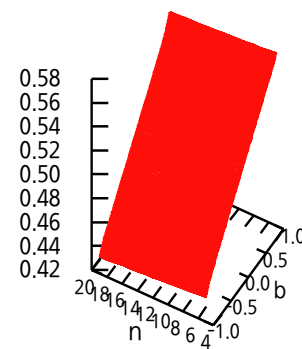

$b(b, n, m=90, s=2)$

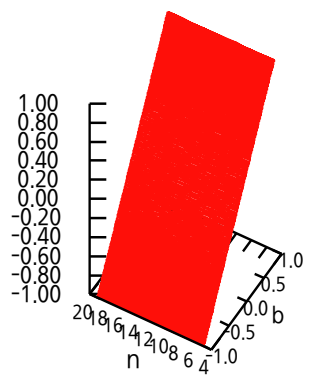

$q(b, n, m=90, s=2)$

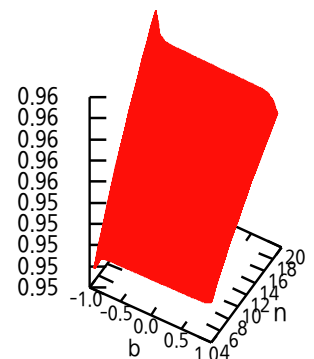

$c(b, n, m=90, s=3)$

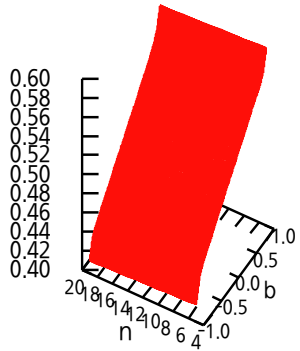

$b(b, n, m=90, s=3)$

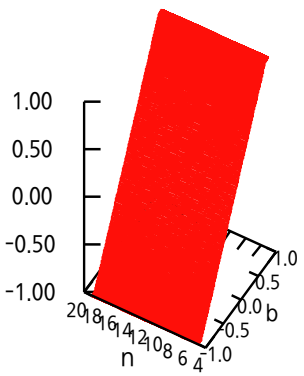

$q(b, n, m=90, s=3)$

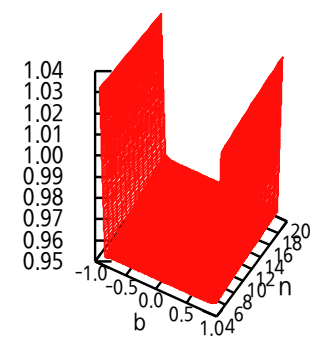




\section{References}

Alvarez, F. and U. J. Jermann (2000), "Efficiency, Equilibrium, and Asset Pricing with Risk of Default," Econometrica 68, pp. 775-797.

Barro, R. J. (2006), "Rare Disasters and Asset Markets in the Twentieth Century," Quarterly Journal of Economics 121, pp. 823-866.

Barro, R. J. and J. F. Ursua (2008), "Macroeconomic Crises since 1870," Brookings Papers on Economic Activity, pp. 255-335.

Barro, R. J., E. Nakamura, J. Steinsson, and J. F. Ursua (2011), "Crises and Recoveries in an Empirical Model of Consumption Disasters," unpublished manuscript.

Beker, P. F. and S. Chattopadhyay (2010), "Consumption Dynamics in General Equilibrium: A Characterization when Markets are Incomplete," Journal of Economic Theory 145, pp. 2133-2185.

Beker, P. F. and E. Espino (2011), "A General Equilibrium Explanation for Financial Market Anomalies: Belief Heterogeneity Under Limited Enforce-ability," unpublished manuscript.

Blume, L. and D. Easley (2006), "If You're So Smart, Why Aren't You Rich? Belief Selection In Complete And Incomplete Markets," Econometrica 74(4), pp. 929-966.

Blume, L., T. Cogley, D. Easley, T. J. Sargent, and V. Tsyrennikov (2012), "Paternalism, Heterogeneous Beliefs, and Market Completeness," unpublished manuscript.

Borovicka, J. (2011), "Survival and Long-Run Dynamics with Heterogeneous Beliefs Under Recursive Preferences," unpublished manuscript.

Cao, D. (2011), "Belief Heterogeneity, Wealth Distribution, and Asst Prices," unpublished manuscript.

Cogley, T. and T. J. Sargent (2009), "Diverse Beliefs, Survival, and the Market Price of Risk," Economic Journal 119, pp. 354-376.

Cogley, T., T. J. Sargent, and V. Tsyrennikov (2012), "Market Prices of Risk with 
Learning, Diverse Beliefs, and Catastrophes," American Economic Review Papers and Proceedings 102(3), pp. 141-146.

Cogley, T., T. J. Sargent, and V. Tsyrennikov (2012b), "Speculation And Wealth When Investors Have Diverse Beliefs And Financial Markets Are Incomplete," unpublished manuscript.

Coury, T. and E. Sciubba (2010), "Belief Heterogeneity and Survival in Incomplete Markets," Economic Theory, forthcoming.

Duffie, D., J. Geanakoplos, A. Mas-Colell, and A. McLennan (1994), "Stationary Markov Equilibria," Econometrica 62, pp. 745-781.

Friedman, M. (1953), Essays in Positive Economics, University of Chicago Press.

Geanakoplos, J. and W. R. Zame (2002), "Collateral and the Enforcement of Intertemporal Contracts," unpublished manuscript.

Guerdjikova, A. and E. Sciubba (2010), "Survival with Ambiguity," unpublished manuscript.

Grossman, Sanford J. (1981), "An Introduction to the Theory of Rational Expectations under Asymmetric Information," Review of Economic Studies 48(4), pp. 541-559.

Heathcote, J., K. Storesletten, and G. Violante (2009), "Quantitative Macroeconomics with Heterogeneous Households," Annual Review of Economics, Vol. 1, pp. 319-354.

Krusell, P. and A. Smith (1998), "Income and Wealth Heterogeneity in the Macroeconomy," Journal of Political Economy 106, pp. 867-896.

Kubler, Felix and H. M. Polemarchakis (2002), "Markov Equilibria In Overlapping Generations," Brown University mimeo.

Kubler, F. and K. Schmedders (2003), "Stationary Equilibria in Asset-Pricing Models with Incomplete Markets and Collateral," Econometrica 71(6), pp. 1767-1793.

Sandroni, A. (2005), "Market Selection when Markets are Incomplete," Journal of Mathematical Economics 41, pp. 91-104. 
Tsyrennikov, V. (2011), "Mechanics of Wealth Dynamics with Heterogeneous Beliefs," unpublished manuscript.

Tsyrennikov, V. (2012), "Proof that debt limits must bind under complete markets," unpublished manuscript. 


\section{$<$ Abstract in Korean $>$}

\section{Timothy Cogley*, Thomas J. Sargent**, Viktor Tsyrennikov***}

본 논문은 경제주체들 간 정보가 비대칭적일 때 금융시장 구조가 경제내 금융자산의 분배에 어떤 영향을 미치는지 이론모형을 이용하여 분석하였다. 모형에서는 미래 상황에 대해 충분한 정보를 가지고 있거나 불충분한 정보를 가지고 있는 두 가지 유형의 경제주체가 존재한다.

금융시장이 완전한 경우 정보가 불충분한 개인들이 자산을 줄이게 되지만 (Blume and Easley, 2006), 금융시장이 불완전한 경우에는 부의 분배가 이와 차별화될 수 있다. 오직 무위험 채권만 거래되는 경제에서는 정보가 불충분한 개인들은 자산을 축적하고, 정보가 충분한 개인들은 자신의 부채 한도까지 빚을 늘리게 된다. 이는 정보가 불충분한 개인들은 미래 상황에 대해 비관적이므로 심각한 경기위축에 대비하여 무위험 채권을 매수하는 반면, 정보가 충분한 개인들은 채권가격 상승에 대응하여 무위험 채권을 매도하기 때문이다.

* New York University.

** New York University and Hoover Institution.

*** Cornell University. 